\title{
Imaging of ICU Patients
}

\author{
Rahul Lohan
}

\subsection{Introduction}

Imaging in intensive care unit (ICU) is integral to patient management. The portable chest radiograph is the most commonly requested imaging examination in ICU, and, despite its limitations, it significantly contributes to the decisionmaking process. Multidetector CT (MDCT) is reserved for relatively complex and challenging clinical scenarios. Bedside ultrasound is emerging as a promising imaging modality as it does not subject the patients to risks and resources involved in the transportation of these patients to the CT facility. Ultrasound is an effective modality to triage patients and is being increasingly incorporated into the emergency and intensive care management algorithms.

The commonly encountered disease states in ICU setting are pulmonary parenchymal diseases, pulmonary thromboembolism, barotrauma, and pleural fluid. Besides the evaluation of these conditions, imaging is routinely used for the assessment of various catheters and tubes commonly used in ICUs.

\subsection{Pulmonary Parenchymal Diseases}

The common pulmonary parenchymal disease processes in ICU patients include hydrostatic pulmonary edema, acute respiratory distress syndrome (ARDS), atelectasis, pneumonia, aspiration, and pulmonary hemorrhage.

R. Lohan $(\varangle)$

Department of Diagnostic Radiology, Khoo Teck Puat Hospital,

Singapore, Singapore

e-mail: lohan.rahul@ktph.com.sg

\subsubsection{Pulmonary Edema}

Pulmonary edema is an abnormal accumulation of fluid in the extravascular compartment of the lungs. The fluid accumulation depends on the capillary permeability and the oncotic pressure, as described by the Starling equation, i.e., $\mathrm{Q}=\mathrm{K}(\mathrm{HPiv}-\mathrm{Hpev})-\mathrm{T}(\mathrm{OPiv}-\mathrm{OPev})$, where $\mathrm{Q}$ represents the amount of fluid filtered and HP and OP denote the hydrostatic and oncotic pressures of the intravascular (iv) and extravascular (ev) compartments. K represents the conductance of the capillary wall, determined by the resistance offered to the water flow by the capillary endothelial cell junctions [1]. $\mathrm{T}$ represents the permeability of the capillary membranes to the macromolecules. Lymphatic drainage is another pathway for handling excess water in the lungs. However, the lymphatic drainage needs time to be effective, and in the acute situation, it often fails to eliminate the excess fluid [2]. Classically grouped into cardiogenic and non-cardiogenic variants, the pulmonary edema can be divided into the following four types based on the pathophysiology [3] (Fig. 7.1):

(a) Increased hydrostatic pressure edema

(b) Permeability edema with diffuse alveolar damage (DAD)

(c) Permeability edema without DAD

(d) Mixed edema

Almost all pulmonary edema presentations in critical care units are due to increased hydrostatic pressure or increased permeability with DAD. The two common pathophysiological forms are further discussed.

\subsubsection{Hydrostatic Pulmonary Edema}

The two most common causes of increased hydrostatic pressure edema (HPE) in critical care units are left heart failure and fluid overload. Besides renal and liver failure, overzealous hydration in settings of trauma and immediate postoperative care frequently contibutes to fluid overload. There are two distinct radiological phases of the 

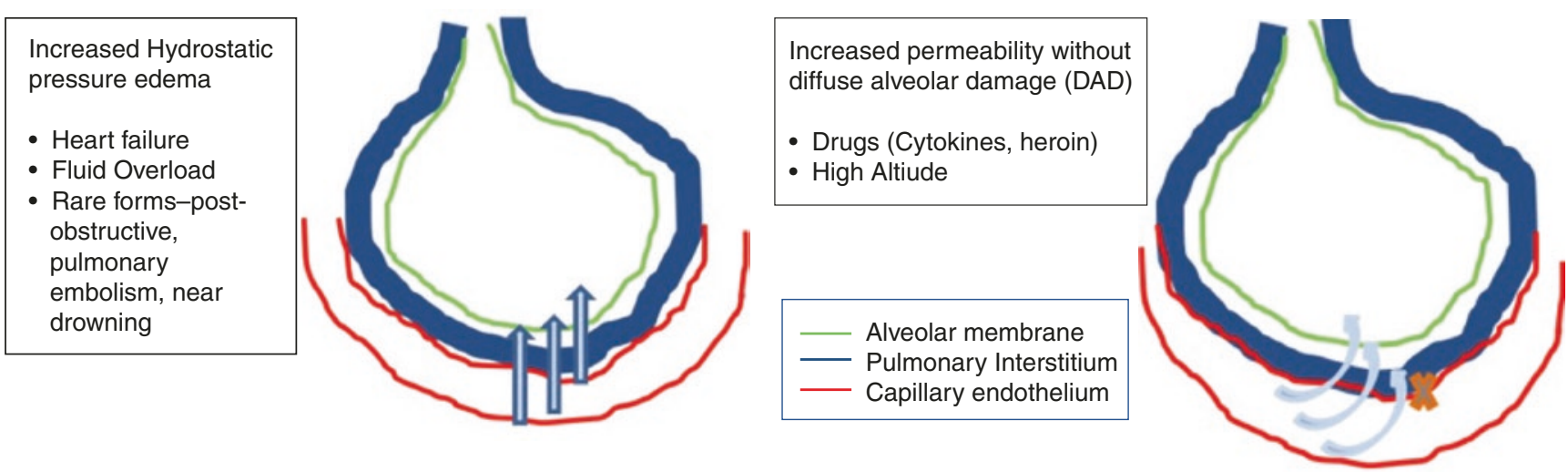

Increased permeability
with diffuse alveolar
damage (DAD)
ARDS
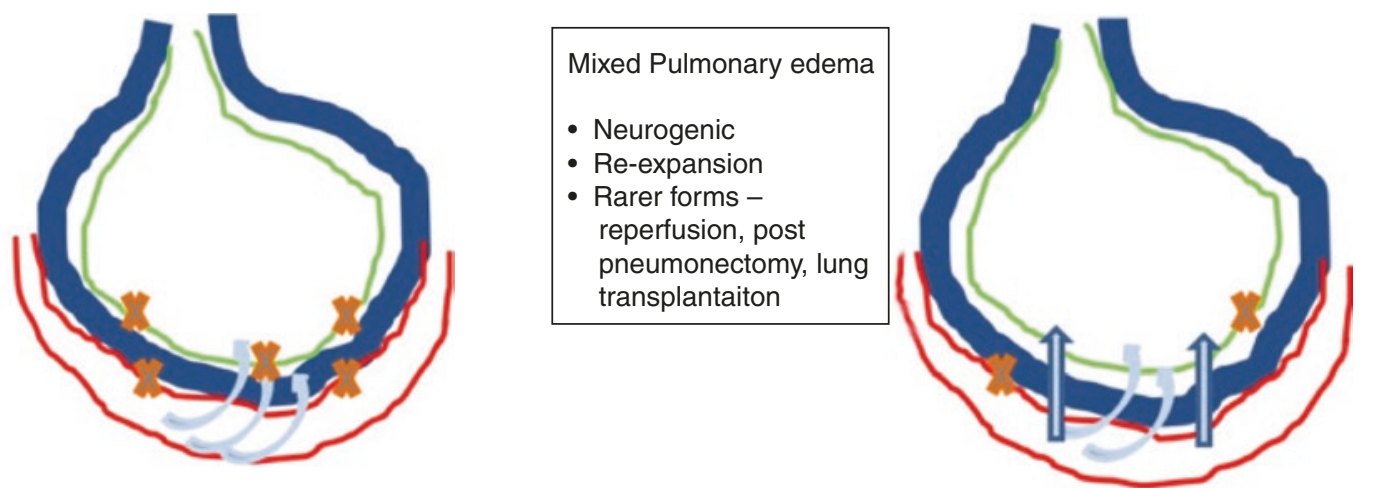

Fig. 7.1 Categories and underlying common etiologies of pulmonary edema on the basis of pathophysiology

pressure edema-the interstitial edema and the alveolar edema. The radiographic findings in the early interstitial phase include indistinctness of the intrapulmonary vasculature, peribronchial cuffing, and Kerley lines. Indistinctness of pulmonary vasculature is subtle but often the most useful radiographic sign of early interstitial edema in ICU patients. With increasing intensity and duration of pressure gradient, edema extends into the alveolar spaces, resulting in nodular or acinar areas of increased opacity that coalesce into frank consolidation (Fig. 7.2). There is a good correlation between the increased pressure in the intravascular compartment as measured by the pulmonary capillary wedge pressure (PCWP) and radiographic appearances (Table 7.1) [4].

The vascular pedicle width is measured from the SVC and azygos vein complex on the right to proximal descending thoracic aorta on the left. It can provide a reasonable estimate of intravascular volume status. Increased width of vascular pedicle $(>7 \mathrm{~cm})$ thus may help in differentiating hydrostatic pulmonary edema from non-cardiogenic edema (Fig. 7.3). The CT findings of hydrostatic pulmonary edema include smooth interlobular septal thickening, ground-glass opacities, consolidation, and pleural effusions (Fig. 7.4). The distribution of densities often demonstrates gravity-based gradient, with abnormalities being most notable at the lung bases. Atypical distribution or appearances similar to aspiration pneumonitis or pneumonia may be seen in presence of underlying chronic pulmonary disease, such as emphysema [5].

\subsubsection{Permeability Edema with Diffuse Alveolar Damage}

Acute respiratory distress syndrome (ARDS) represents the most severe form of permeability edema associated with DAD [2, 3]. In ICU settings, the common primary pulmonary pathologies causing ARDS are pneumonia, aspiration, and pulmonary contusions. The common extrathoracic causes include drug toxicity, systemic inflammatory response syndrome, sepsis, shock, and abdominal trauma [5]. Clinically, ARDS is defined by recently created "Berlin defi- 
nition" (Table 7.2) [6]. ARDS involves three often overlapping and conflicting stages. The first or exudative stage is characterized by a rapidly progressing high protein content interstitial edema that quickly fills the alveoli and is associated with hemorrhage and hyaline membrane formation. The second or proliferative stage involves organization of the fibrinous exudate, regeneration of the alveolar lining, and thickening of the alveolar septa. The third or fibrotic stage manifests as varying degrees of scarring and formation of subpleural and intrapulmonary cysts.

The radiographic findings in exudative phase are that of interstitial edema pattern, rapidly progressing to perihilar opacities and subsequently widespread alveolar consolidation (Fig. 7.5). In comparison to hydrostatic edema,
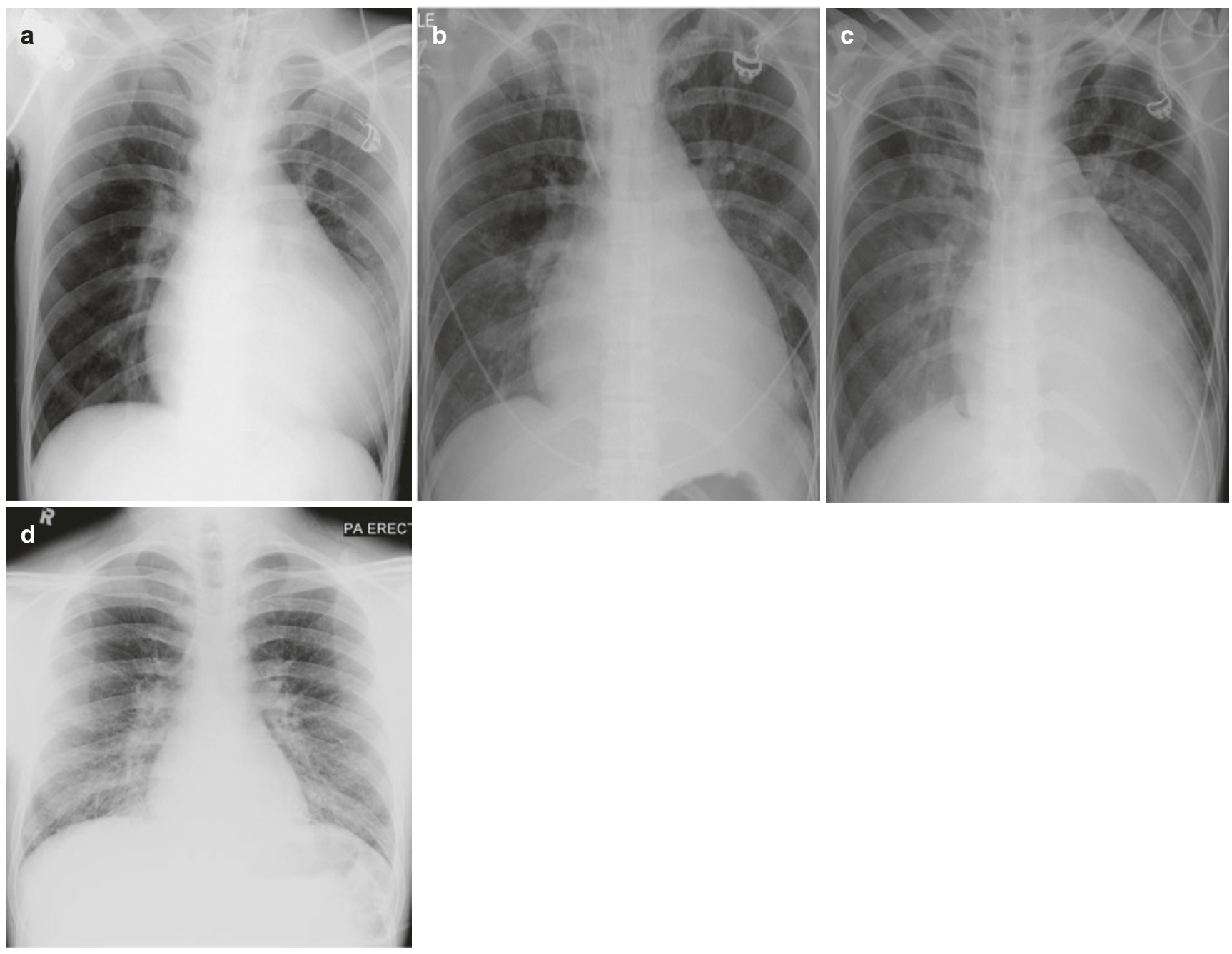

Fig. 7.2 Radiographic progression of hydrostatic pulmonary edema. (a) AP bedside chest radiograph obtained in a patient with acute myocardial infarction demonstrates redistribution of pulmonary vessels with upper lobe diversion upon admission to ICU. (b) Next day radiograph demonstrates features of interstitial edema in the form of indistinctness of pulmonary vessels and bilateral perihilar haziness. (c) Progression to bilateral central consolidation and small pleural effusions representing alveolar edema is seen on the radiograph obtained on

the third day. Pulmonary edema in another patient. (d) Frontal radiograph at presentation shows interstitial thickening. (e-g) Axial CT images demonstrate peribronchial cuffing, septal thickening, gravitydependent ground-glass opacities, and early alveolar opacities (arrows) and bilateral pleural effusions. (h) Follow-up radiograph after 2 days shows resolution of interstitial edema but persistent pleural effusions and bibasilar atelectasis 

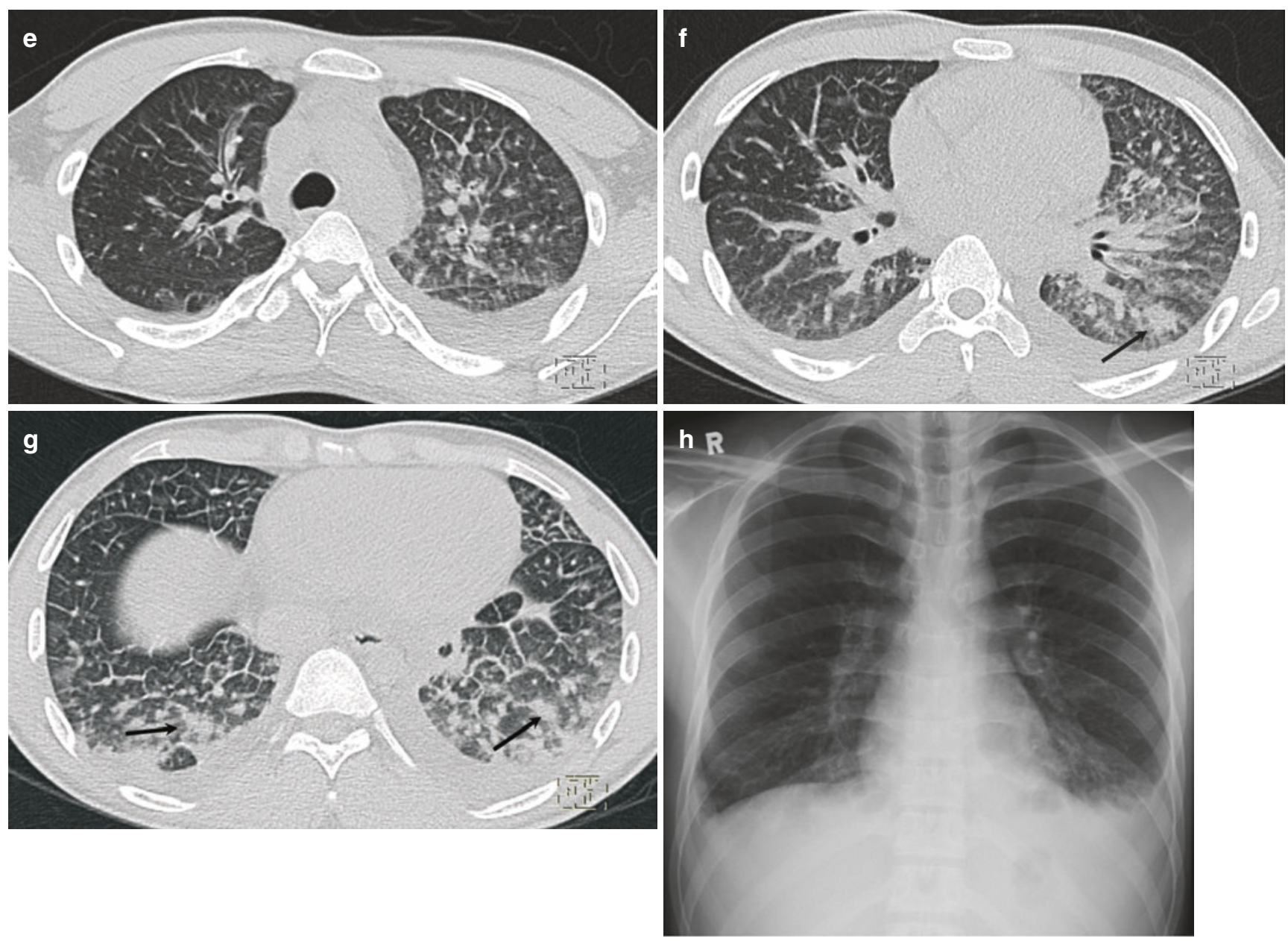

Fig. 7.2 (continued)

Table 7.1 Stages of hydrostatic pulmonary edema

\begin{tabular}{|c|c|c|}
\hline & PCWP & Radiographic changes \\
\hline $\begin{array}{l}\text { Stage } 1 \\
\text { Redistribution }\end{array}$ & $13-18 \mathrm{~mm} \mathrm{Hg}$ & $\begin{array}{l}\text { - Redistribution of pulmonary } \\
\text { vessels } \\
\text { - Cardiomegaly } \\
\text { - Increased vascular pedicle } \\
\text { width }\end{array}$ \\
\hline $\begin{array}{l}\text { Stage } 2 \\
\text { Interstitial } \\
\text { edema }\end{array}$ & $18-25 \mathrm{~mm} \mathrm{Hg}$ & $\begin{array}{l}\text { - Kerley lines } \\
\text { - Peribronchial cuffing } \\
\text { - Hazy contour of vessels }\end{array}$ \\
\hline $\begin{array}{l}\text { Stage } 3 \\
\text { Alveolar } \\
\text { edema }\end{array}$ & $>25 \mathrm{~mm} \mathrm{HG}$ & $\begin{array}{l}\text { - Central consolidation } \\
\text { - Bat wing appearance } \\
\text { - Pleural effusion }\end{array}$ \\
\hline
\end{tabular}

the alveolar edema in ARDS usually has a more peripheral distribution (Fig. 7.6) [3]. The typical CT findings in this phase are dense consolidation in posterior dependent portions of the lung with ground-glass opacities in nonde- pendent areas (Fig. 7.7). This gravitational distribution can be changed by patient's position (supine vs prone), suggesting a significant contribution from atelectasis [3]. The atypical pattern comprises of dense consolidation in anterior (in supine position) nondependent locations. This may be seen in up to 5\% of ARDS patients and is more common in ARDS with underlying primary pulmonary cause [7]. "Crazy paving," i.e., ground-glass opacities with superimposed inter- and intralobular septal thickening, may be seen [8].

During the fibroproliferative stage, patchy heterogeneous areas of ground-glass opacification are seen with reticular changes. Traction bronchiectasis and bronchiolectasis may be seen on CT. These findings early in the course of ARDS are associated with a poorer clinical outcome [9]. Subpleural and intrapulmonary cystic lesions may be observed in the fibrotic stage which can directly result in pneumothoraces 


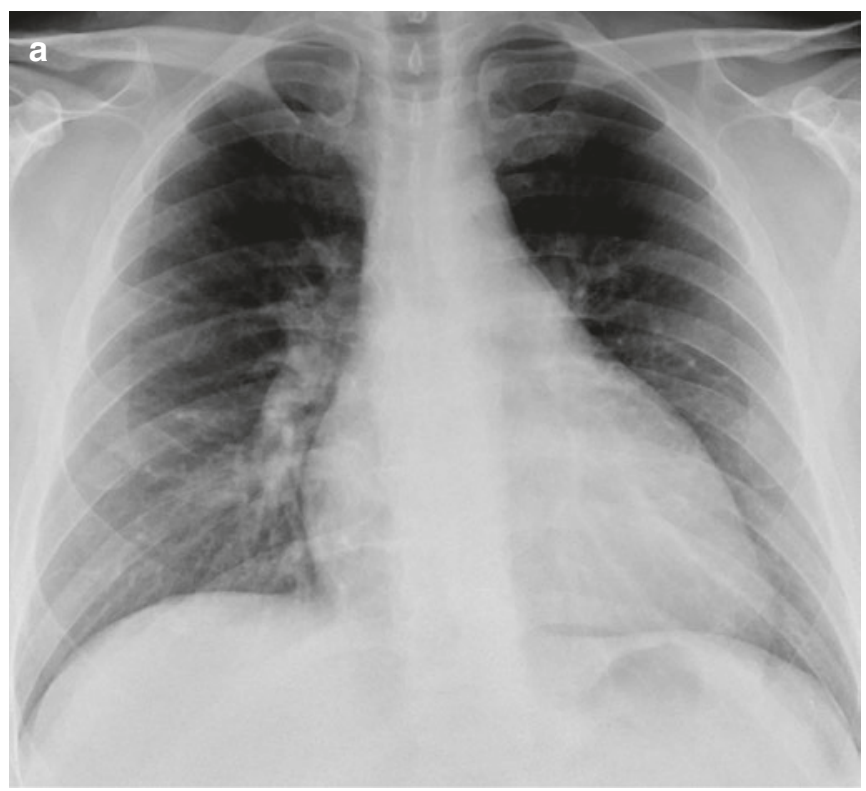

Fig. 7.3 Interstitial pulmonary edema from congestive cardiac failure. (a) Baseline AP chest radiograph and (b) early stage of pulmonary edema demonstrating progressively increasing width of vascular pedi-

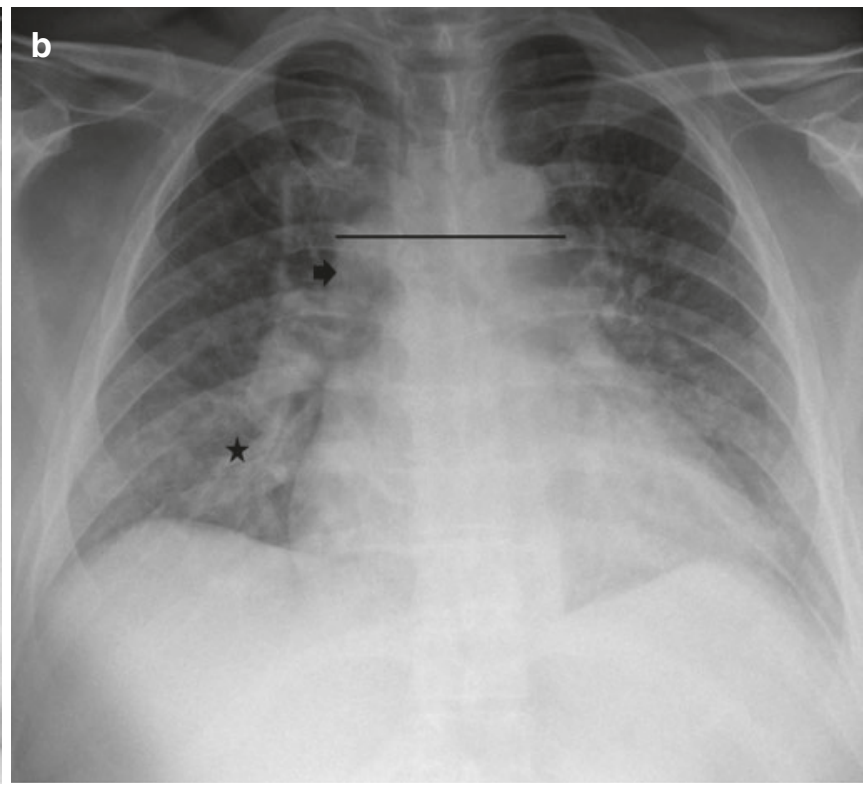

cle (as represented by the line), enlarged central vessels (arrow), and indistinctness of pulmonary vessels (asterisk)

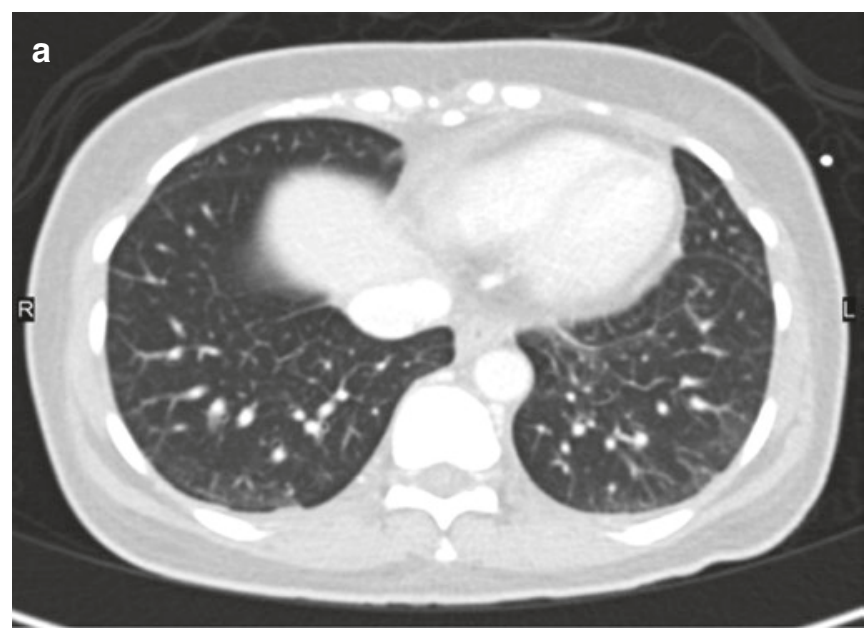

Fig. 7.4 CT findings of hydrostatic pulmonary edema. (a) Axial CT images in lung window show smooth interlobular septal thickening at lung bases during the early stage of pulmonary edema, (b) progressing

[9]. Recurrent episodes of exudative phase in the proliferative and fibrotic stages often result in mixed radiologic findings. HRCT of the patients recovered from ARDS on subsequent follow-up shows characteristic anterior lung fibrotic bands with sparing of posterior lungs. Distinguishing imaging features between HPE and ARDS are described in Table 7.3.

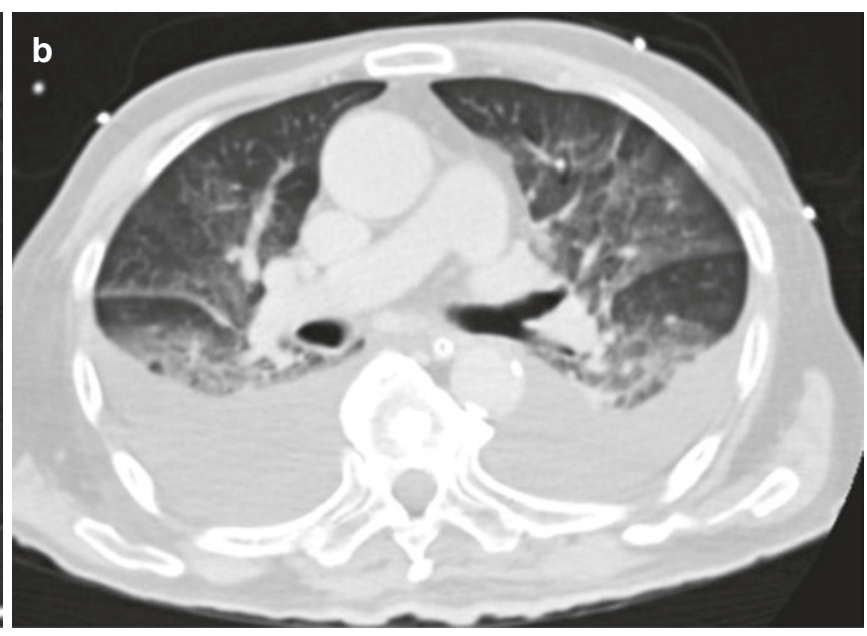

to symmetrical central ground-glass opacities and bilateral pleural effusions at a later stage. Note there is a gravity-based gradient of increasing density in the lungs

\subsubsection{Atelectasis}

Atelectasis, defined as a decrease in lung volume, is the commonest cause of radiographic parenchymal opacities in ICU patients, particularly amongst the postoperative surgical ICU patients. The atelectasis most commonly involves the left lower lobe (66\%), followed by the right lower lobe (22\%) and right 
Table 7.2 The Berlin definition of ARDS

\begin{tabular}{l|l}
\hline Timing & $\begin{array}{l}\text { Within 1 week of known insult or new or worsening } \\
\text { respiratory symptoms }\end{array}$ \\
\hline $\begin{array}{l}\text { Origin of } \\
\text { edema }\end{array}$ & $\begin{array}{l}\text { Respiratory failure not explained by cardiac failure } \\
\text { or fluid overload, objective evidence to exclude } \\
\text { hydrostatic pulmonary edema (e.g., } \\
\text { echocardiography) if no clinical risk factors }\end{array}$ \\
\hline $\begin{array}{l}\text { Chest } \\
\text { imaging }\end{array}$ & $\begin{array}{l}\text { Bilateral opacities-not fully explained by effusion, } \\
\text { lobar/lung collapse, or nodules }\end{array}$ \\
\hline Oxygenation & $\begin{array}{l}\text { Mild, moderate, severe; } \mathrm{PaO} / \mathrm{FiO} 2 \text { ratio of } \\
300-200,200-100, \text { and }<100, \text { respectively }\end{array}$ \\
\hline
\end{tabular}
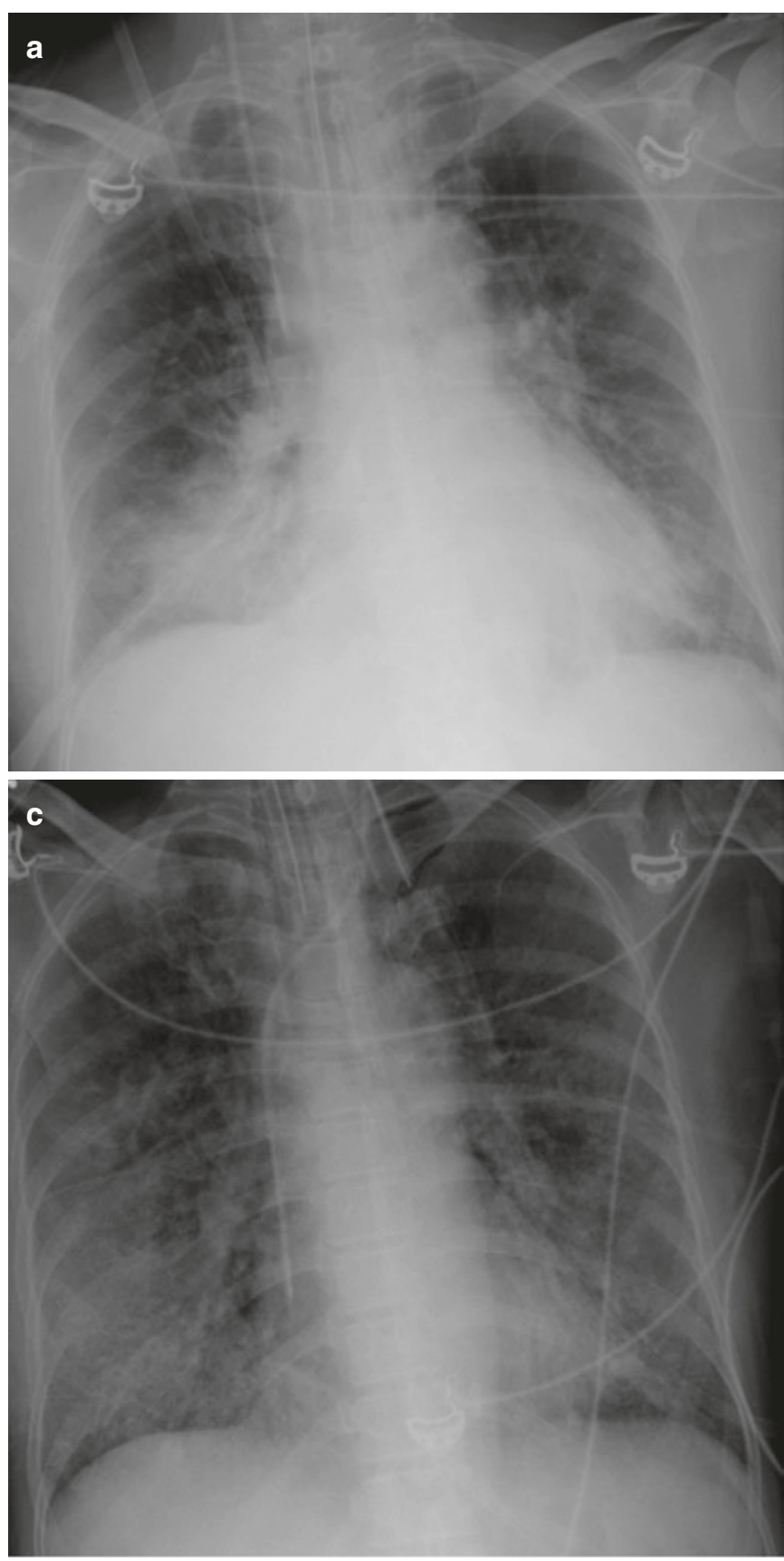

Fig. 7.5 Acute respiratory distress syndrome (ARDS). (a) AP bedside chest radiograph of a patient admitted to ICU with severe pneumonia demonstrates dense right lower zone consolidation from pneumonia, (b) rapidly progressing to extensive bilateral central consolidation upper lobe (11\%) [10]. Obstructive atelectasis from impaired mucociliary clearance, increased secretions, and altered consciousness is often encountered in the ICU patients. Distal obstruction manifests as crowding of air bronchograms, whereas the proximal mucus plugging leads to lobar or even complete lung collapse (Fig. 7.8). Compressive atelectasis from pleural effusion and cicatrization from fibrosis in later stages of ARDS are other forms of atelectasis seen in ICU setting. The imaging findings include linear, band-like, or wedge-shaped opacities with signs of volume loss.

b

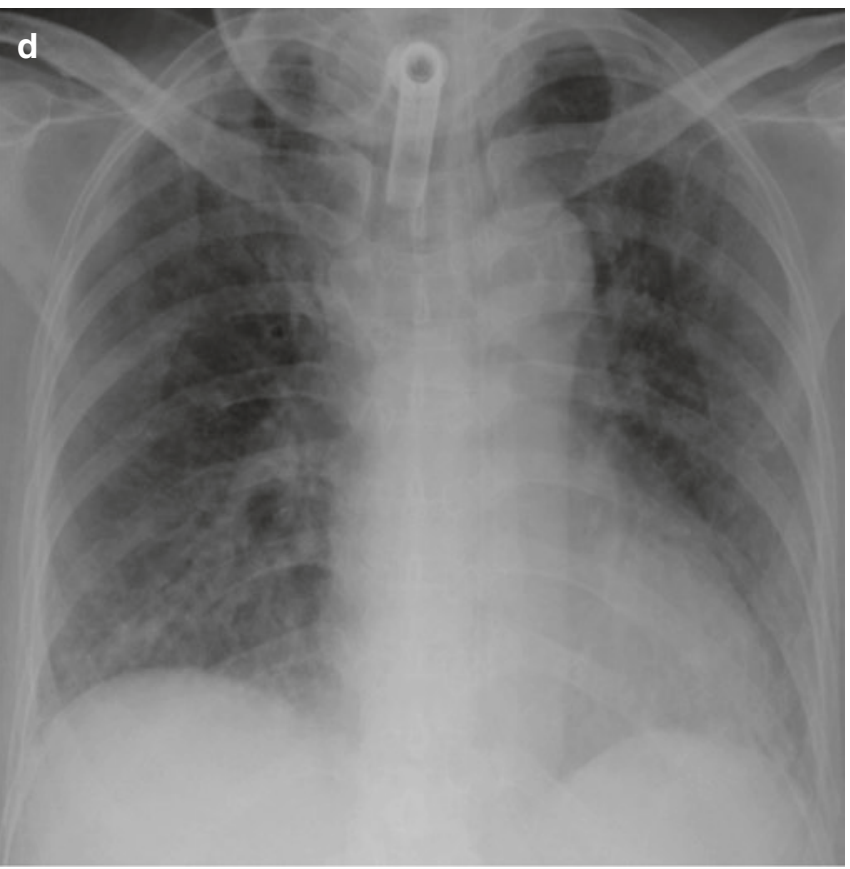

representing the exudative phase of ARDS. (c) Follow-up radiographs during extended ICU stay show bilateral reticulonodular opacities and (d) patchy linear opacities with some volume loss in the fibrotic phases 

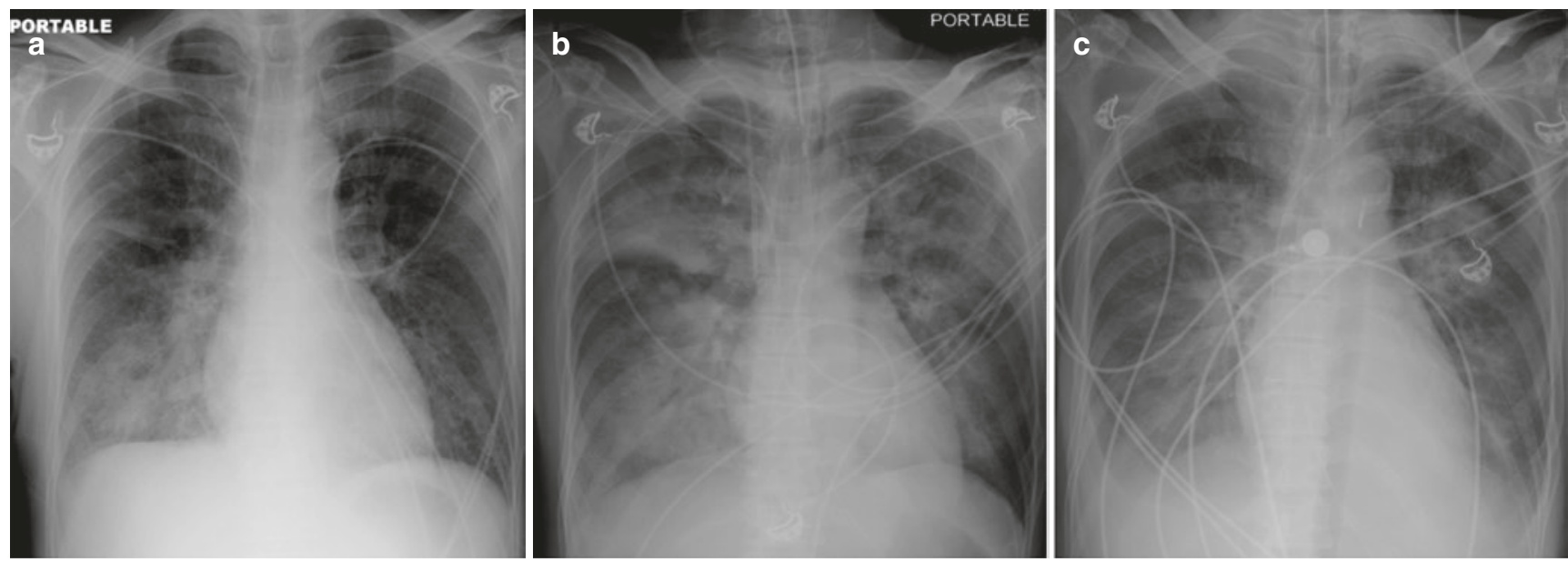

Fig. 7.6 ARDS vs hydrostatic pulmonary edema. (a) AP chest radiograph in a patient with pneumonia demonstrates right midand lower zone consolidation (b) rapidly progressing to bilateral extensive asymmetrical central consolidation with air bronchograms representing an exudative phase of ARDS. (c) AP chest radiograph of the same patient obtained 1 month later during ICU stay for acute myocardial infarction demonstrates bilateral symmetrical central consolidation with bilateral pleural effusions from alveolar phase of hydrostatic pulmonary edema. Note the intraaortic balloon pump

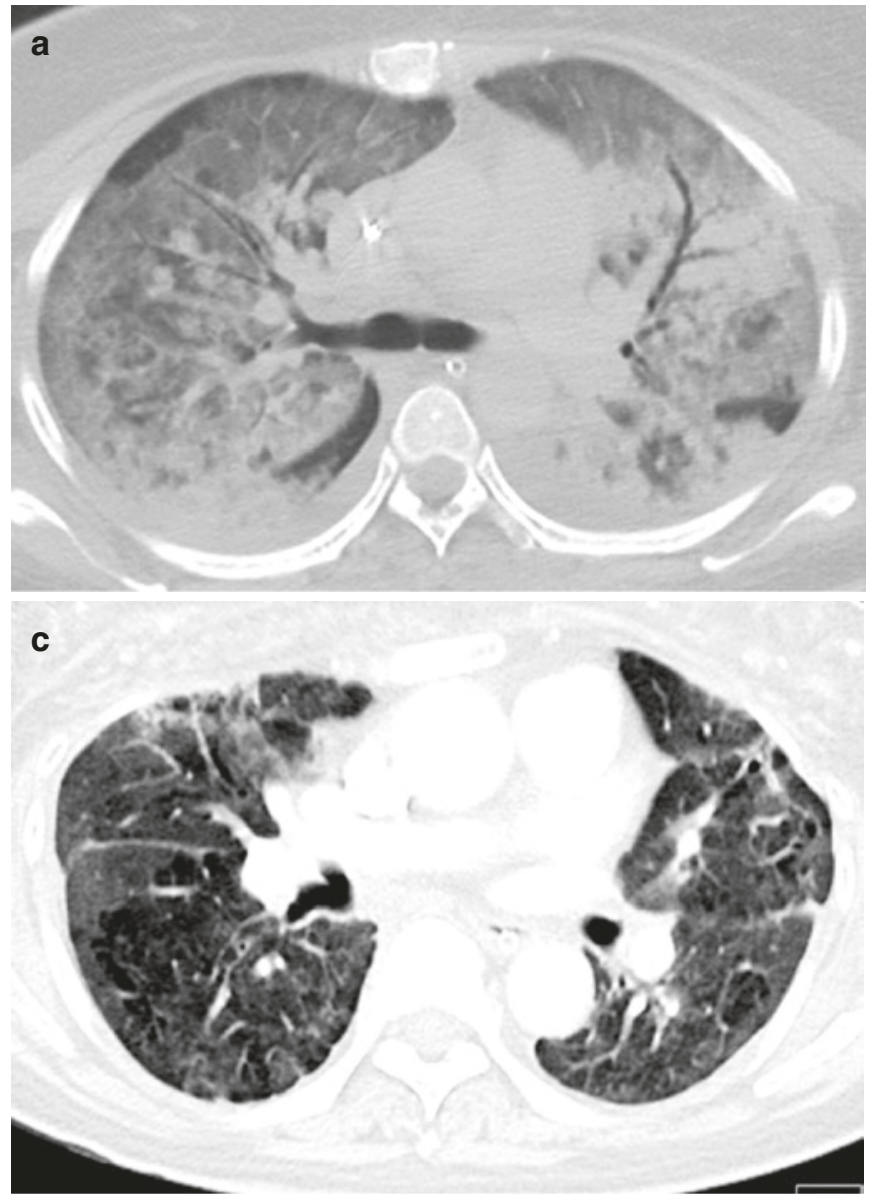

Fig. 7.7 CT features of ARDS. (a) Axial CT images in lung window demonstrating exudative phase of ARDS with bilateral dense consolidation in the dependent posterior parts of the lungs and ground-glass

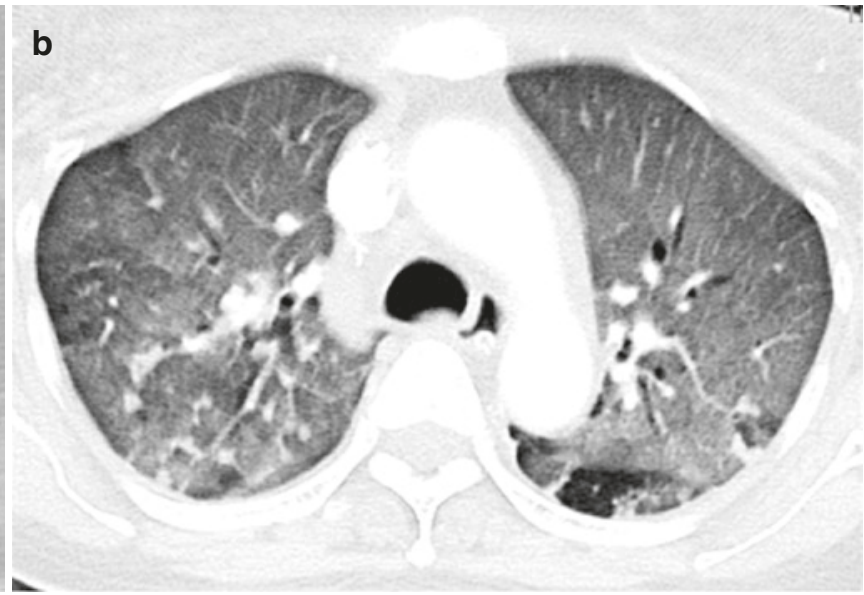

densities anteriorly. This gravitational gradient may change with prone position. (b) During later phase, reticular changes with ground-glass opacities are seen, $(\mathbf{c})$ which progress to patchy areas of scarring 
Table 7.3 Imaging clues: HPE vs ARDS

\begin{tabular}{l|l|l}
\hline & HPE & ARDS \\
\hline Heart size & Usually increased & Often normal \\
\hline $\begin{array}{l}\text { Vascular pedicle } \\
\text { width }\end{array}$ & Increased or normal & Normal \\
\hline $\begin{array}{l}\text { Distribution of } \\
\text { opacities }\end{array}$ & $\begin{array}{l}\text { Central, even, often } \\
\text { symmetric }\end{array}$ & $\begin{array}{l}\text { Peripheral, patchy, } \\
\text { often asymmetric }\end{array}$ \\
\hline Air bronchograms & Usually absent & Common \\
\hline Pleural effusion & Very common & Not common \\
\hline Course & Opacities clear fast & $\begin{array}{l}\text { Opacities last longer } \\
\text { May progress to fibrotic } \\
\text { phase }\end{array}$ \\
\hline
\end{tabular}

\subsubsection{Pneumonia}

Mechanical ventilation and aspiration are two main risk factors for pneumonia in ICU patients. Ventilator-associated pneumonia can occur in up to $24 \%$ of patients after 2 days of ventilation [11]. The diagnosis of pneumonia in ICU patients is often challenging as the airspace opacities seen on chest radiographs in these patients can be caused by atelectasis, aspiration, pulmonary hemorrhage, noninfectious lung inflammation (e.g., drug reaction), pulmonary edema, or
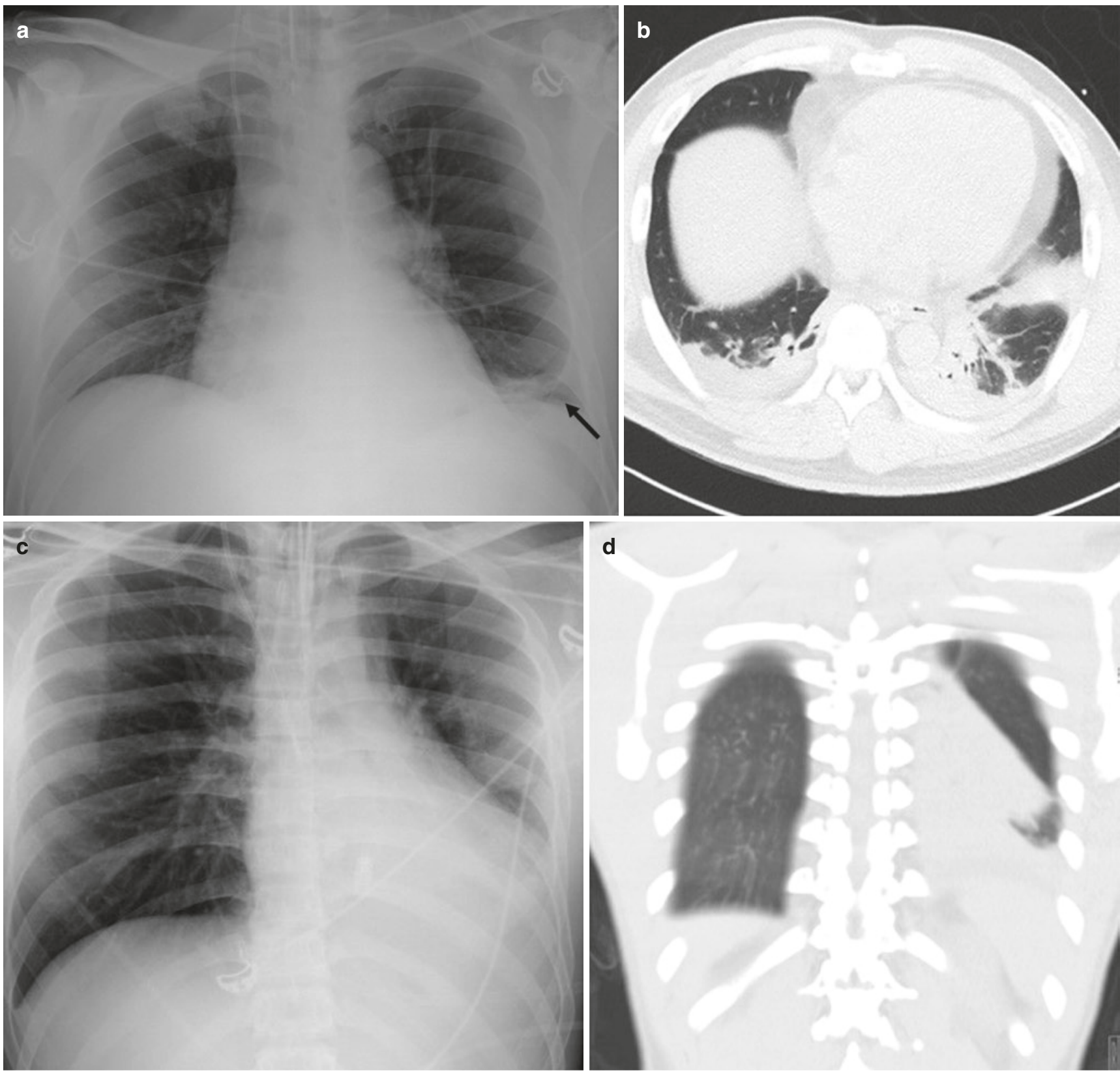

Fig. 7.8 Atelectasis. (a) AP chest radiograph of a postoperative patient demonstrates band-like opacity in the left lower zone. (b) Corresponding axial CT image in lung window demonstrates bilateral lower lobe densities with crowding of airways and wedgeshaped opacity in the lingula. (c) AP chest radiograph in another patient demonstrates left retrocardiac opacity with silhouetting of hemidiaphragm and signs of volume loss in the left lung. (d) Coronal CT image confirms the radiographic findings of left lower lobe collapse which often occurs from mucus plugging of the lobar bronchus in ICU patients 
ARDS [12]. However, there are certain features that may favor pneumonia (Table 7.4). Air bronchograms typically associated with pneumonia result from the complete filling of the alveolar spaces around nonobstructed bronchi. However, when the airways get filled with mucus, air bronchograms are not seen on imaging which is often the case in critically ill patients (Fig. 7.9).

On CT, pneumonia can often be differentiated from atelectasis by lack of signs of volume loss. CT may provide additional clues to the possible causative agent of pneumonia. Cavities, upper lobe or superior segment of lower lobe airspace disease, endobronchial spread (tree-in-bud densities), and findings of prior granulomatous disease point toward reactivation tuberculosis (TB). Multiple peripheral lung nodules, solid as well as cavitary, in certain patients (long-term indwelling catheters, endocarditis, or history of IV drug abuse) suggest septic emboli [12]. Widespread bilateral predominantly central ground-glass opacities and cysts with or without spon-

Table 7.4 Imaging features of pneumonia and atelectasis

\begin{tabular}{l|l}
\hline Pneumonia & Atelectasis \\
\hline Confluent or nodular opacities & $\begin{array}{l}\text { Opacities often linear, band-like, } \\
\text { or wedge-shaped (lobar) }\end{array}$ \\
\hline $\begin{array}{l}\text { Opacities resolve slowly } \\
\text { (except aspiration pneumonia) }\end{array}$ & $\begin{array}{l}\text { Opacities appear and resolve } \\
\text { rapidly }\end{array}$ \\
\hline No signs of volume loss & $\begin{array}{l}\text { Signs of volume loss: } \\
\text { Crowding of air bronchograms } \\
\text { Fissural deviation } \\
\text { Mediastinal shift } \\
\text { Diaphragmatic elevation }\end{array}$ \\
\hline $\begin{array}{l}\text { Barely enhances on contrast- } \\
\text { enhanced CT as the exudates } \\
\text { in alveoli are not vascularized }\end{array}$ & $\begin{array}{l}\text { Acute atelectasis enhances but } \\
\text { chronic atelectasis may not } \\
\text { enhance }\end{array}$ \\
\hline
\end{tabular}
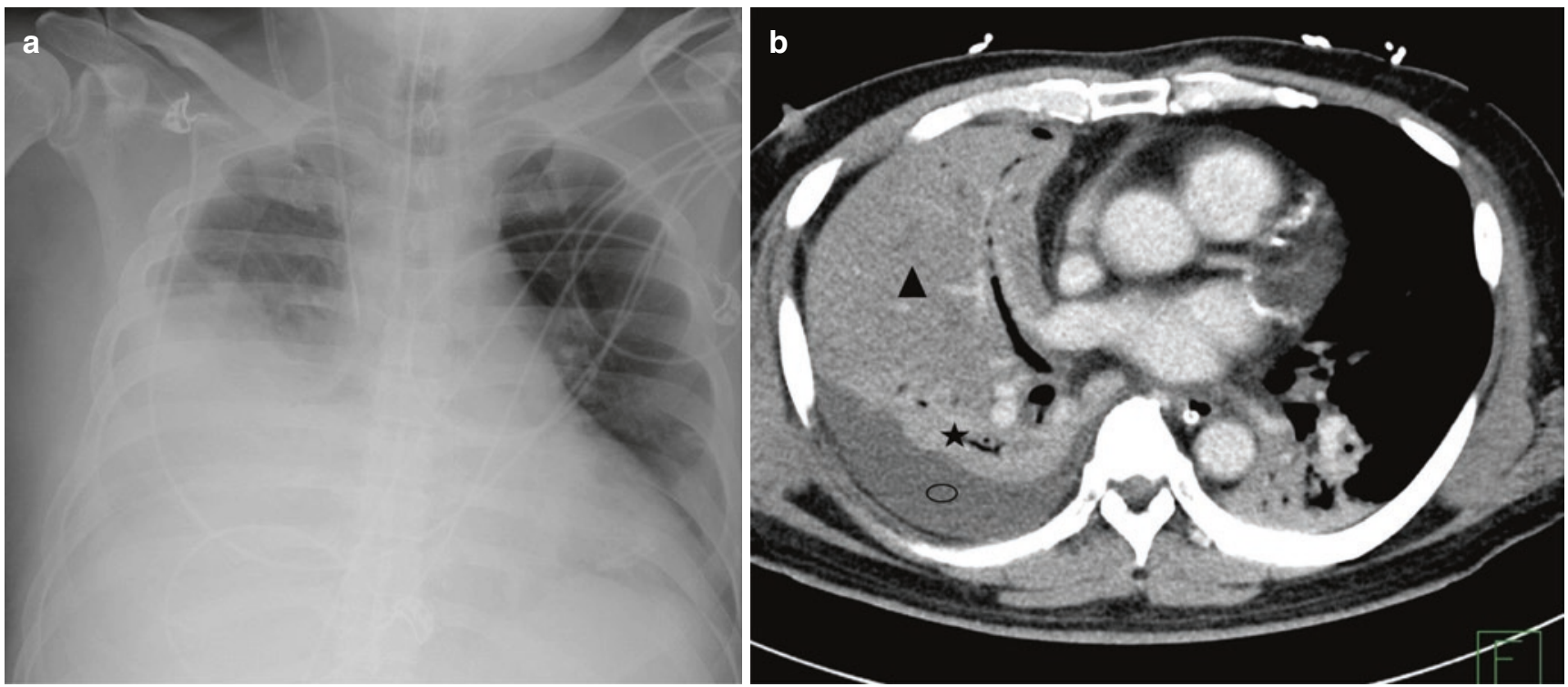

Fig. 7.9 Pneumonia. (a) AP chest radiograph of a patient admitted to ICU for severe community-acquired pneumonia demonstrates right midto lower zone dense opacity. (b) Axial CT image shows the radiographic opacity to be composed of a low attenuation anterior area of consolida- taneous pneumothorax in immunocompromised patients are features of Pneumocystis jiroveci pneumonia (PCP), whereas focal areas of consolidation surrounded by a "halo" of groundglass suggest angioinvasive aspergillosis [13].

\subsubsection{Aspiration}

Intubation, diminished cough reflex, sedation, altered mental state, and enteric tube feeding predispose the ICU patients to increased risk of aspiration. The different manifestations of the aspiration include chemical pneumonitis, pneumonia, and airway obstruction. Aspiration of large amounts of severely acidic gastric contents can be fatal, resulting in a severe chemical pneumonitis and ARDS [14].

Aspiration is more common in the right lung, due to the vertical orientation of the right main bronchus. In the supine position, the frequently involved sites are the posterior segments of the upper lobes and superior segment of the lower lobe [12]. The radiographic abnormalities commonly seen with aspiration are patchy ill-defined ground-glass opacities, nodular opacities, or consolidation in the dependent regions of the lungs (Fig. 7.10). The opacities usually are seen over the first 1-2 days in aspiration pneumonitis demonstrating relatively rapid resolution on follow up radiographs. Persisting opacities indicate progression to infectious pneumonia, and this is one important reason for following up the patients on radiographs. The CT better demonstrates the ground-glass changes or consolidation. Areas of necrosis and cavitation can be seen when aspirates contain anaerobic organisms [12]. Tree-in-bud opacities present in the abovementioned dependent distribution are also frequently seen with aspiration [8]. tion with no air bronchograms from pneumonia (black triangle), higher attenuation atelectasis in the middle (asterisk), and dependent fluid density pleural effusion posteriorly (open circle). A combination of atelectasis and pneumonia is present in the left lower lobe 

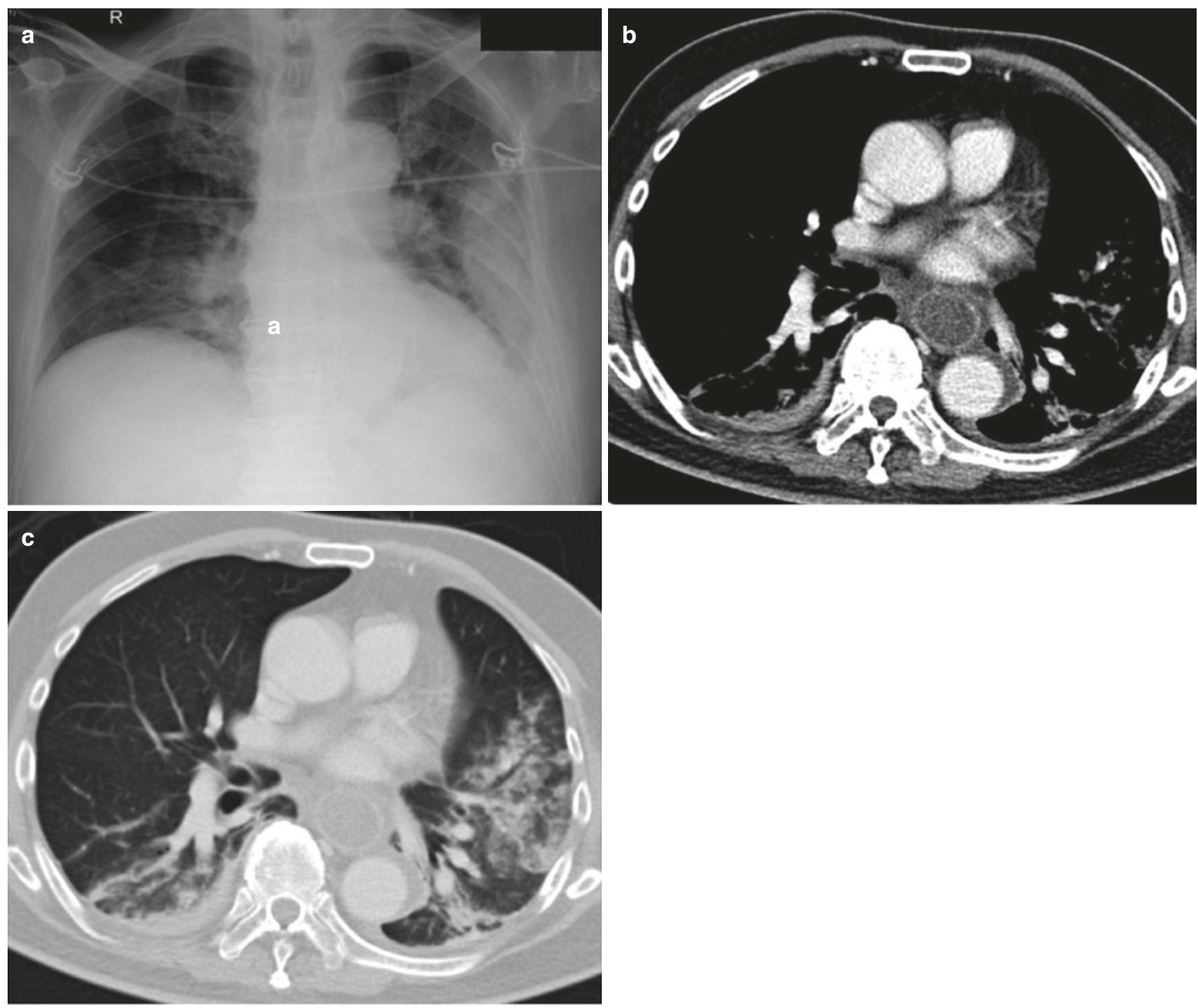

Fig. 7.10 Aspiration. (a) AP chest radiograph of a patient with gastric outlet obstruction shows consolidation in peripheral left lung and right central paracardiac region. (b) Axial CT image in the soft-tissue window reveals a fluid-filled distended esophagus and

\subsubsection{Pulmonary Hemorrhage}

The pulmonary hemorrhage can be localized or diffuse. The localized form is often secondary to bronchiectasis, tumors, or some infections. The diffuse alveolar hemorrhage results from injury to the alveolar microcirculation leading to bleeding into the air spaces [15]. This form is encountered in various autoimmune diseases, bleeding diathesis, vasculitis, certain drugs, and infections (invasive aspergillosis, mucormycosis). In ICU patients, the culprit drugs often are systemic or catheter-directed thrombolytics (for myocardial infarction, PE, or stroke).

The differentiation of pulmonary hemorrhage from pneumonia or pulmonary edema may be difficult. Rapidly

patchy opacities in both lower lobes. (c) Axial CT image in lung window demonstrates ill-defined ground-glass changes, nodular densities, and patchy consolidation in the dependent regions of both lungs

developing central and basilar predominant pulmonary parenchymal opacities sparing the costophrenic angles, along with drop in hemoglobin and hemoptysis (or blood in tracheal aspirate), should suggest the diagnosis of pulmonary hemorrhage. On CT scan, patchy ground-glass opacities, typically cloud-like opacities without significant interlobular septal thickening, are seen in the acute phase. In subacute phase, interlobular and intralobular interstitial thickening often develops [15]. Although the CT imaging features are nonspecific, the distribution of these findings, the temporal evolution of opacities, and the radiologic manifestations of predisposing disease (Table 7.5) can help in arriving at the diagnosis $[15,16]$ (Fig. 7.11). 
Table 7.5 Imaging clues to the cause of diffuse alveolar hemorrhage

\begin{tabular}{l|l}
\hline Wegener's granulomatosis & Cavities, tracheal involvement \\
\hline Goodpasture's syndrome & $\begin{array}{l}\text { Central (edema-like), no pleural } \\
\text { effusion }\end{array}$ \\
\hline SLE & Pleural and pericardial effusions \\
\hline Churg-Strauss syndrome & $\begin{array}{l}\text { Peripheral predominance, } \\
\text { centrilobular nodules, pleural } \\
\text { effusions }\end{array}$ \\
\hline $\begin{array}{l}\text { Long-standing pulmonary } \\
\text { venous hypertension }\end{array}$ & $\begin{array}{l}\text { Enlarged left atrium, mitral valve } \\
\text { prosthesis/calcifications }\end{array}$ \\
\hline
\end{tabular}

\subsection{Pulmonary Thromboembolism}

The prevalence of pulmonary embolism (PE) in critically ill patients is as high as $27 \%$ with only one-third of these cases being suspected clinically [17]. Besides the general risk factors for PE such as obesity, past history of venous thromboembolism, cancer, immobilization, trauma, and recent surgery; the ICU patients are exposed to additional risk factors [18] like sepsis, vasopressor use, pharmacologic seda-
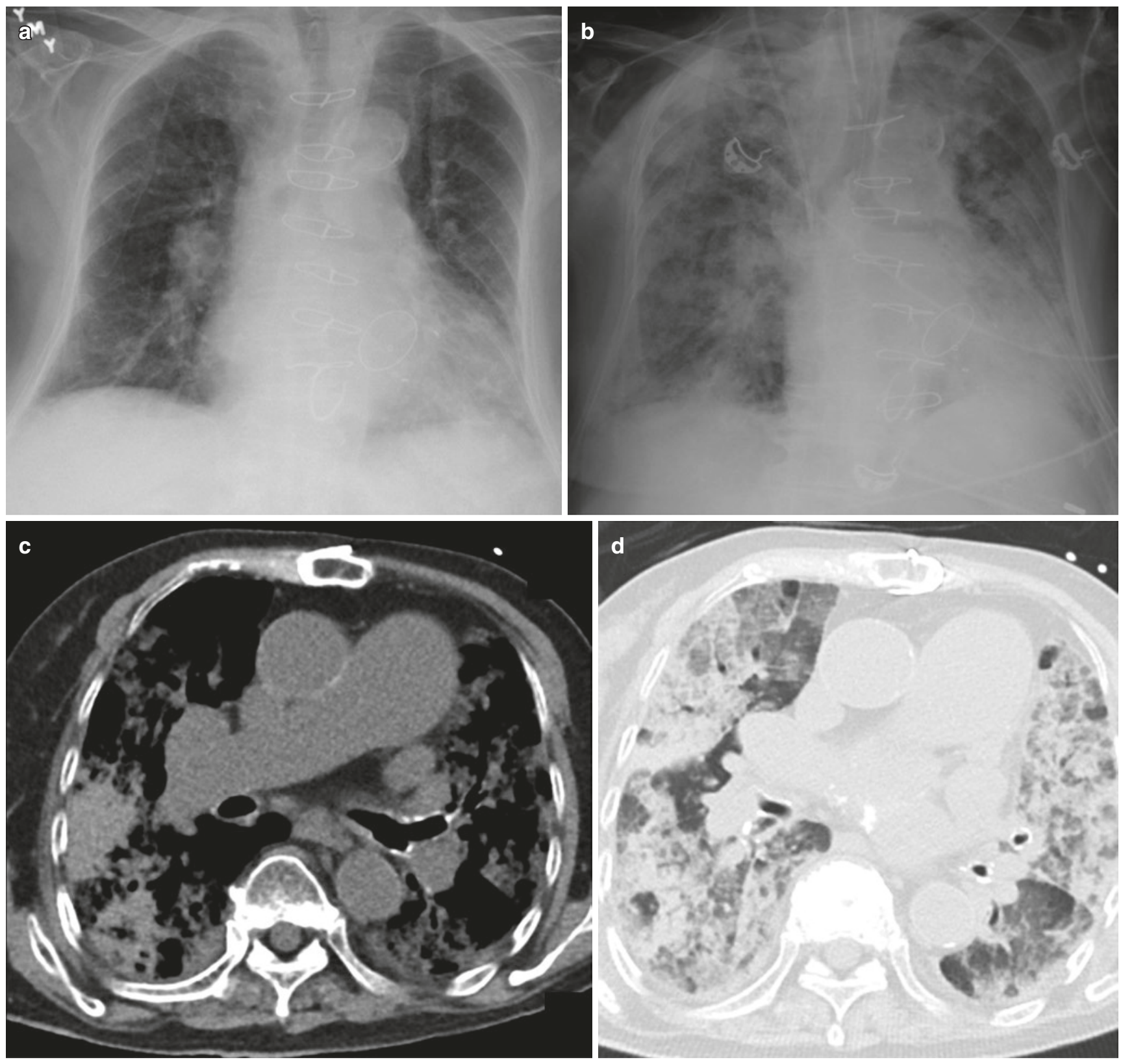

Fig. 7.11 Diffuse alveolar hemorrhage from parainfluenza virus infection. (a, b) AP chest radiographs taken a day apart, show rapidly progressing diffuse opacities in both lungs with no significant pleural effusion. (c) Axial non-contrast CT image shows widespread high attenuation (higher than muscle) patchy consolidation in both lungs. (d) On lung window, there are patchy diffuse ground-glass changes and areas of consolidation with no gradient 
tion, mechanical ventilation, central venous catheters, and renal failure.

There are various radiographic signs (Table 7.6) described for PE [19-22]. Although these signs are difficult to interpret, their timely recognition might alert the physician to the possibility of PE before it is suspected clinically (Figs. 7.12 and 7.13).
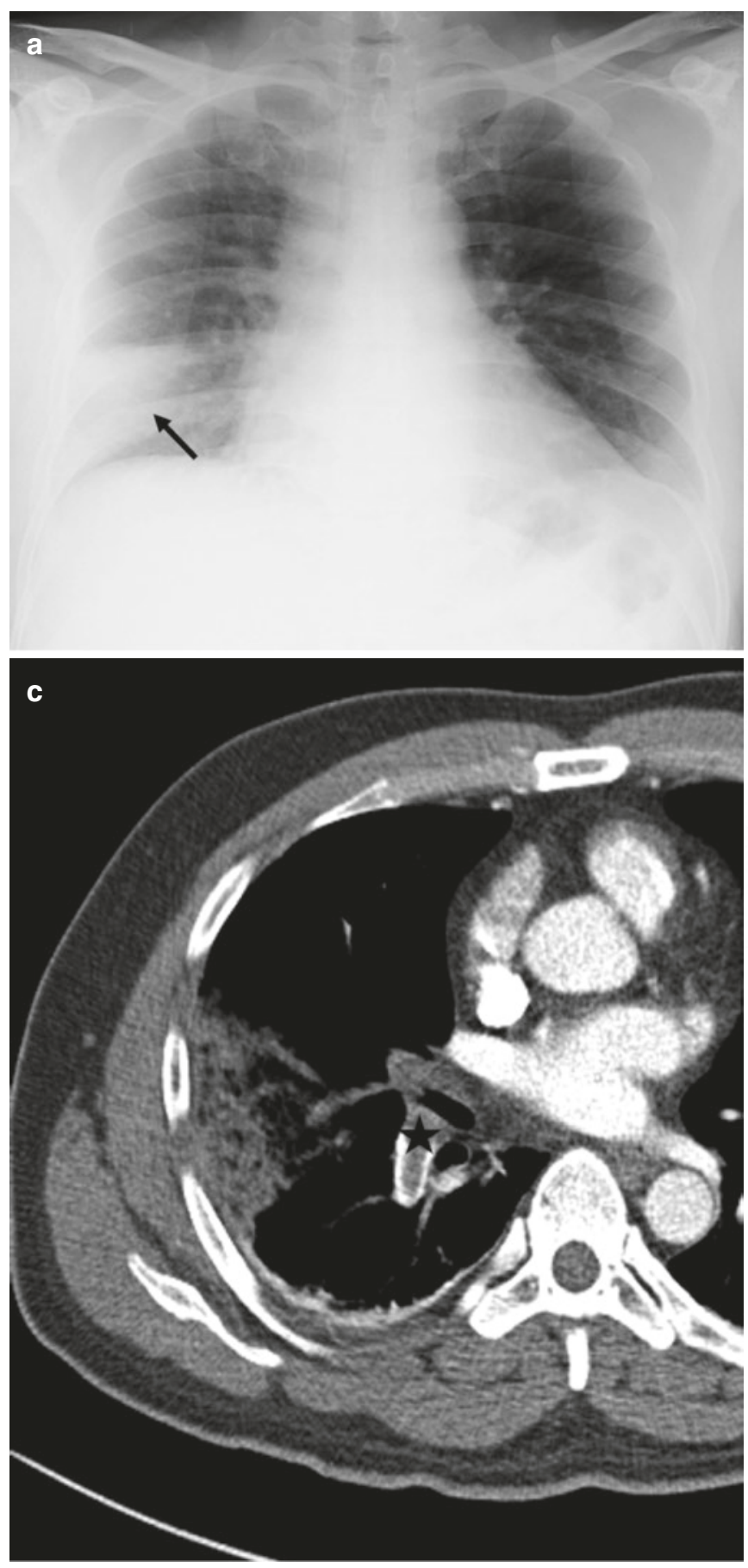

Fig. 7.12 Hampton's hump. (a) Peripheral wedge-shaped opacity (black arrow) in right lower zone on AP chest radiograph in a patient with suspected pulmonary thromboembolism. (b, c) Axial CT images
Table 7.6 Radiographic signs of pulmonary embolism

Westermark sign: regional pulmonary oligemia

Fleischner sign: enlargement of the proximal pulmonary arteries

Knuckle sign: abrupt tapering of the occluded pulmonary artery Hampton's hump: peripheral wedge-shaped opacity without air bronchograms

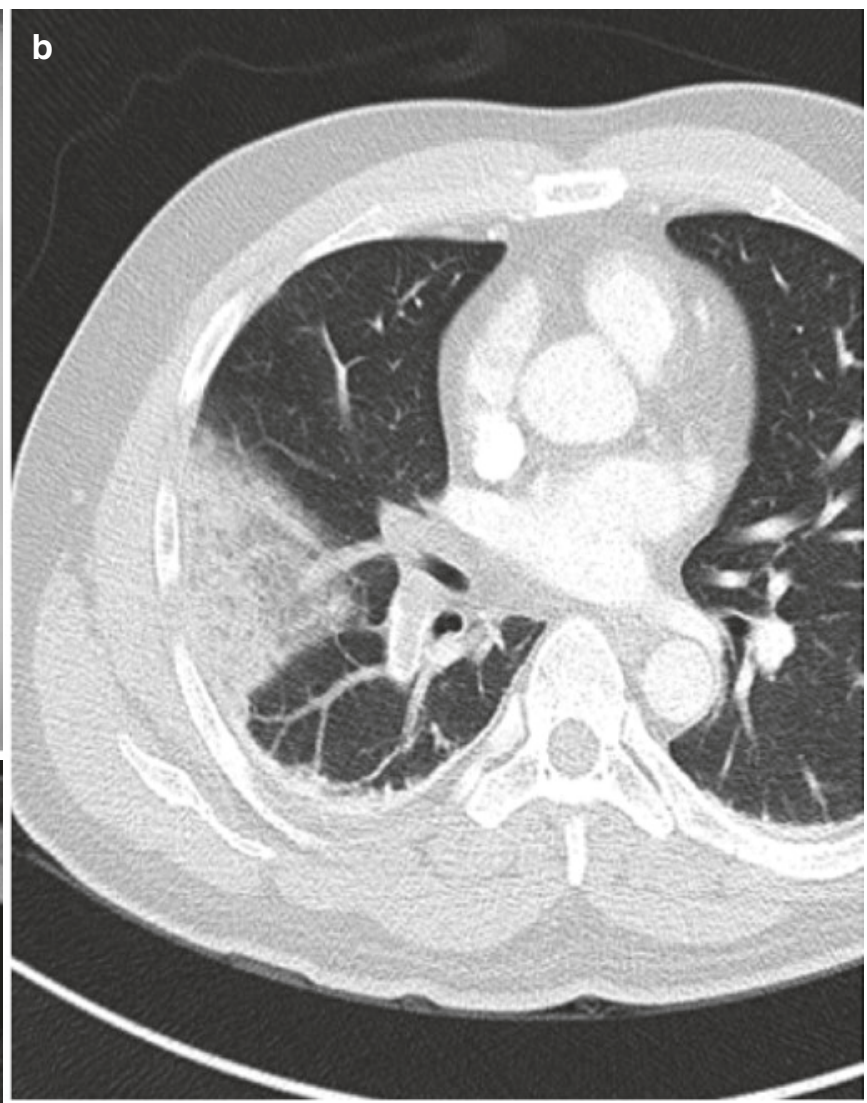

in lung and soft-tissue windows show the typical wedge-shaped configuration of a pulmonary infarct with underlying occlusive thrombus in the right lower lobar artery (asterisk) 

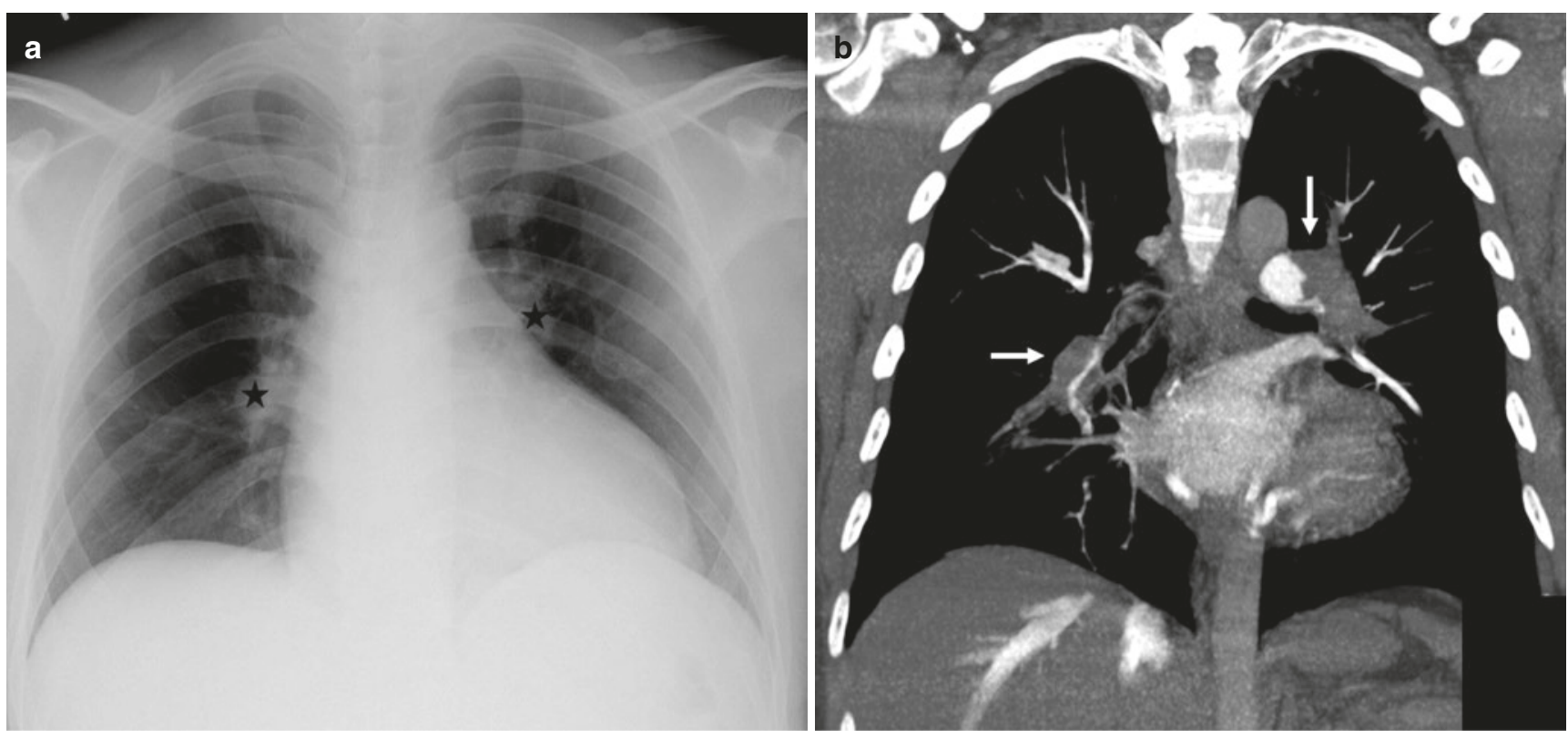

Fig. 7.13 Pulmonary embolism. (a) AP chest radiograph shows bilateral upper and mid-zone oligemic regions with increased lung parenchymal lucency (Westermark sign) along with abrupt truncation

CT pulmonary angiography (CTPA) is now the reference standard for diagnosing PE in ICU patients, with most ICUs moving away from the ventilation-perfusion scan and conventional invasive pulmonary angiography. CTPA not only detects PE by direct visualization of the thrombus in pulmonary arteries, it allows risk stratification by providing signs of right heart strain and quantification of thrombus burden. An RV/LV ratio > 0.9-1.5 has been shown to predict adverse outcomes similar to the echocardiographic measurements [23]. Newer CT techniques, such as dual-energy CT, can be used to assess functional lung perfusion [24] as well as reduce contrast burden in ICU patients who are prone to acute kidney injury [25].

\subsection{Barotrauma}

Barotrauma, particularly the pneumothorax, remains a common ICU complication despite continuously improving mechanical ventilation strategies of low tidal volumes and plateau pressures [26]. The other forms of barotrauma are pneumomediastinum, pneumopericardium, pneumoperitoneum, subcutaneous emphysema, and interstitial emphysema. Even a small pneumothorax can rapidly progress to tension pneumothorax in ventilated patients. The typical appearance of a thin curvilinear line, bordered by the lung on one side and pleural air space devoid of lung markings on the other, is often absent in the supine radiographs. (arrows) of the right interlobar and left lower lobar arteries (Knuckle sign). (b) Coronal thick MIP CT image shows large thrombi in left main and right interlobar arteries (arrows)

In the supine position, air collects to the least dependent anteromedial pleural space (Fig. 7.14) resulting in increased radiolucency at the bases and sharply elongated cardiophrenic and costophrenic sulci (the deep sulcus sign) [27]. $\mathrm{CT}$ is useful for evaluation of loculated air collections and guides the proper placement of chest tube when pneumothorax persists.

Pneumomediastinum (Fig. 7.15) in ventilated patients most commonly occurs from the rupture of the terminal airways. The pressure gradient between an alveolus and the interstitium directs the air from the ruptured alveolus to the perivascular and peribronchial fascial sheath. The fascial sheath at the lung root gives away letting the air escape into the mediastinum. With increasing severity, the air overflows into the subcutaneous tissues of the neck and into the retroperitoneum [28]. Pneumomediastinum can also be seen in tracheobronchial injury, following tracheostomy tube placement, asthma, and esophageal rupture.

\subsection{Pleural Fluid}

Pleural effusion in ICU patients is mostly transudative. Despite being a common occurrence, it is difficult to detect small to moderate pleural fluid on the supine radiograph. In addition, differentiating it from other causes of lower zone opacities such as consolidation and atelectasis is often not possible. The costophrenic angle is often not blunted on the 

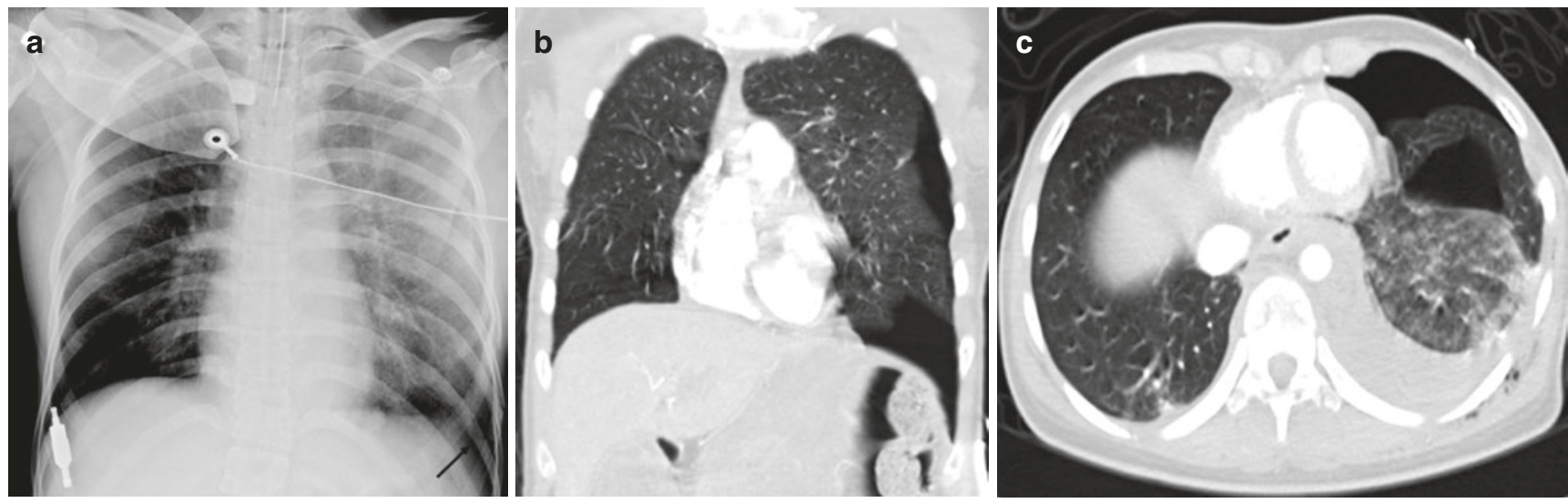

Fig. 7.14 Posttraumatic pneumothorax. (a) Supine chest radiograph shows increased lucency at the left lung base with an elongated left costophrenic sulcus (deep sulcus sign). (b) Coronal CT image confirms the presence of a pneumothorax. (c) Axial CT image demonstrates that the air collects at the most nondependent anterior- medial pleural space on supine position, leading to increased lucency at the lung bases and cardiophrenic angle on the radiograph. Also, note the presence of hemothorax resulting in diffuse haziness over the left lung on the radiograph despite the preserved costophrenic angle

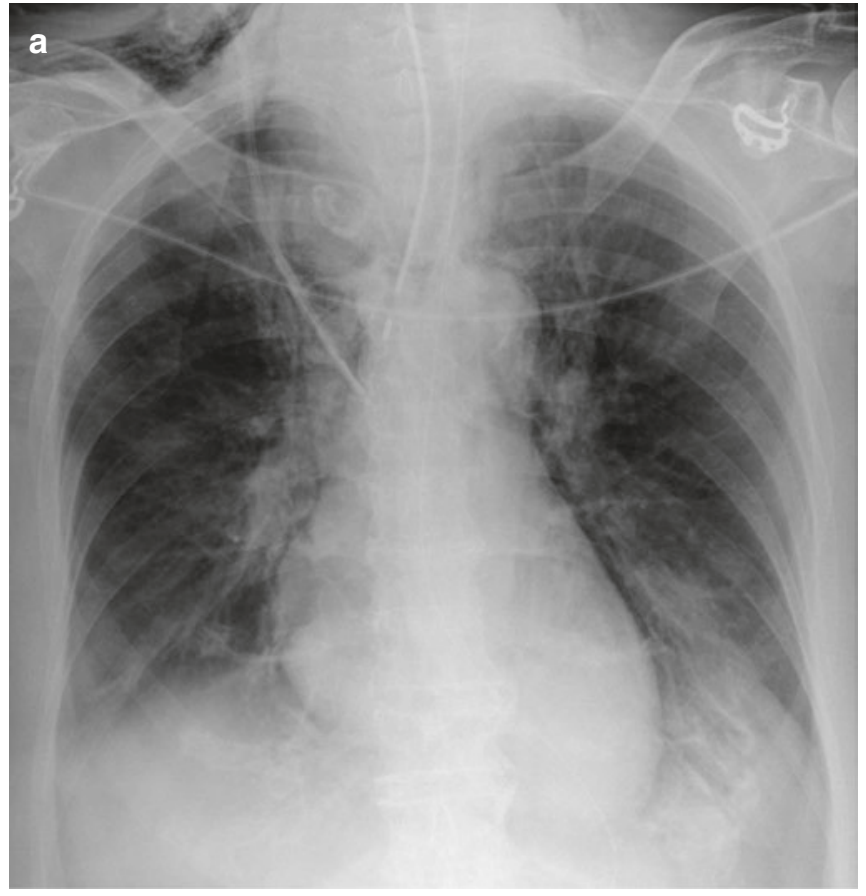

Fig. 7.15 Barotrauma. (a) AP chest radiograph in a ventilated patient demonstrates subcutaneous emphysema at the neck base and pneumomediastinum (thin lucencies outlining the arch of aorta, heart borders,

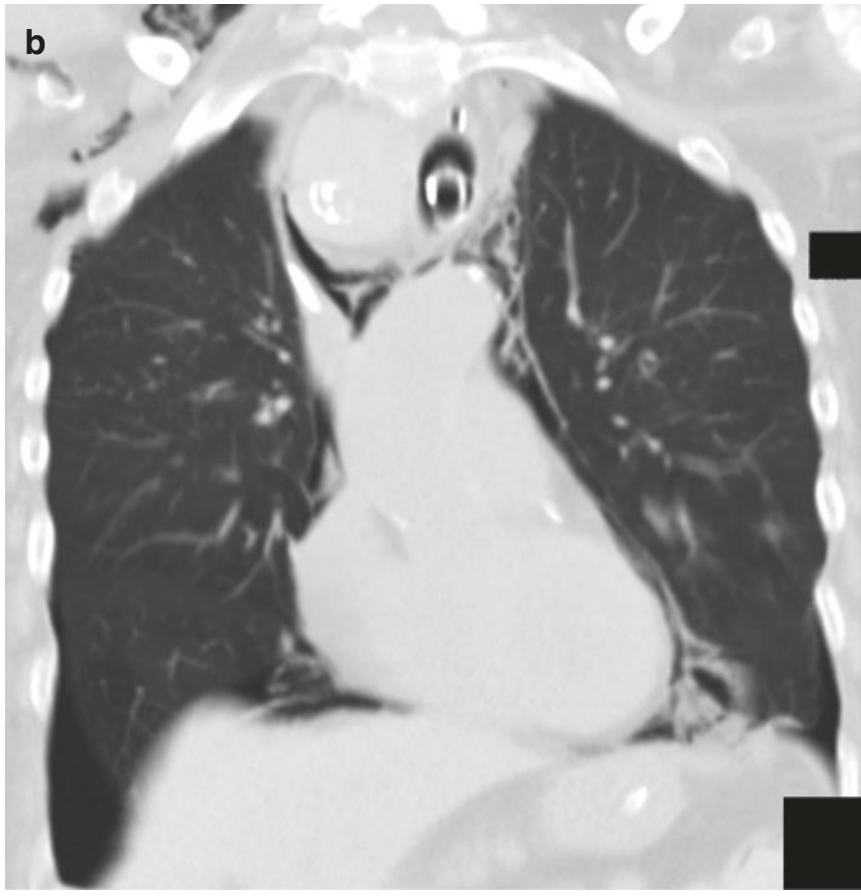

and superior vena cava). (b) Coronal CT image demonstrates the extent of pneumomediastinum and also shows bilateral pneumothoraces from ventilator-related barotrauma supine radiograph, and pleural fluid may only demonstrate diffuse hazy "veil-like" opacification from the layering of the pleural fluid (Fig. 7.16). The apex is the most dependent location in supine patients and fluid may manifest as an apical cap [29].

CT helps in differentiating pleural fluid from pulmonary parenchymal disease and better demonstrates the loculated pleural fluid collections. On CT, the thick enhancing visceral and parietal pleura suggests empyema often with a "split pleura" sign. Hemothorax is suggested by increased attenuation of the pleural fluid, commonly 35-70 HU [30]. Ultrasound, readily available as a bedside imaging modality in most ICUs, is very useful in demonstrating loculations and in guiding fluid sampling as well 

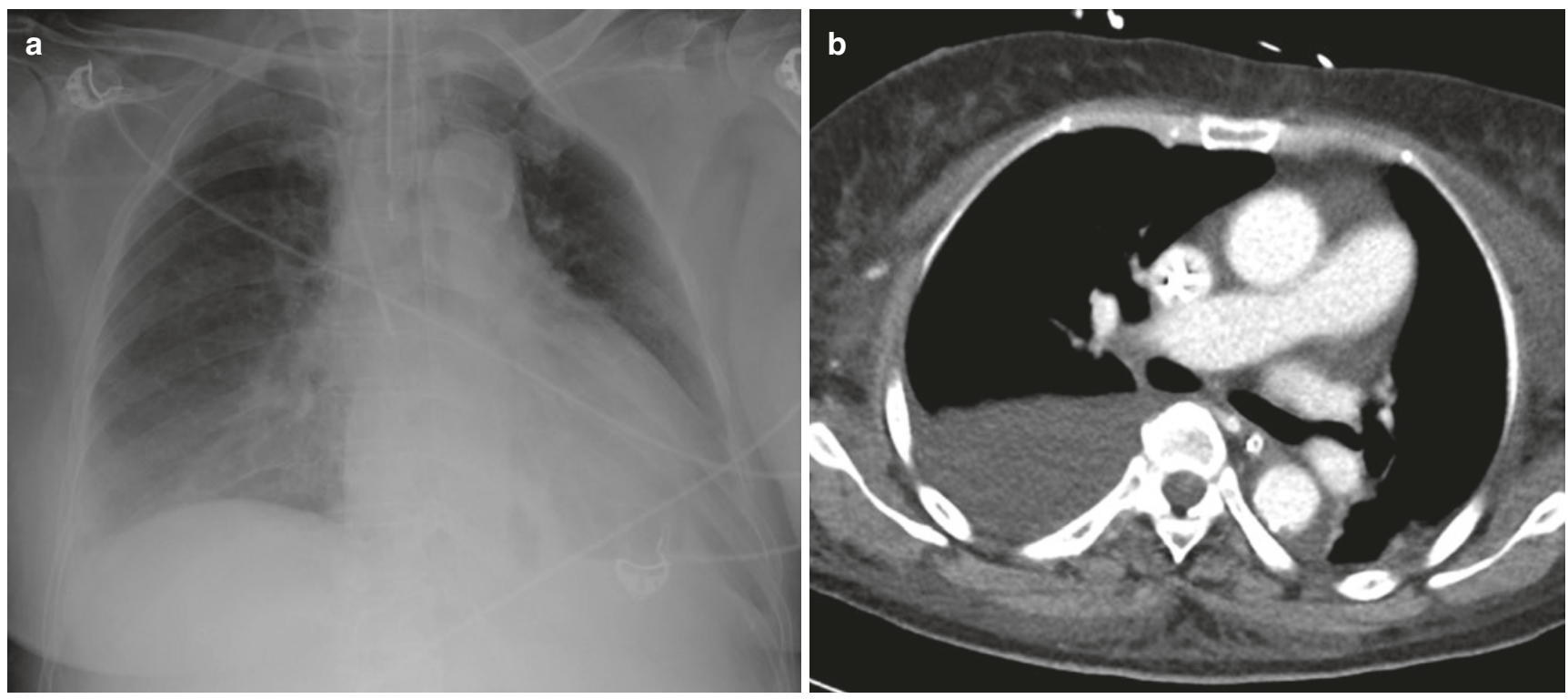

Fig. 7.16 Pleural effusion. (a) Supine AP chest radiograph demonstrates diffuse hazy "veil-like" opacification of the right mid- and lower zones, often the only radiographic sign of pleural effusion in ICU patients. (b) Axial CT image shows moderate right pleural effusion

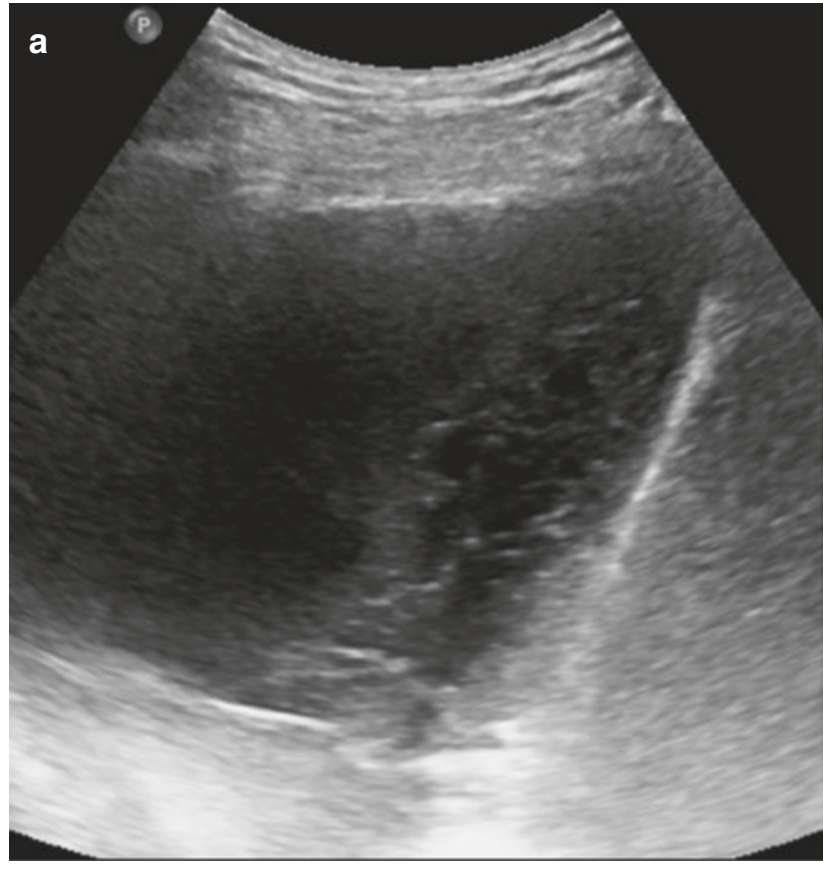

Fig. 7.17 Empyema. (a) Bedside ultrasound examination in a patient with pneumonia demonstrates moderate right pleural effusion with irregular echogenic strands (honeycomb appearance). (b) Coronal CT

as therapeutic drainage. On ultrasound examination, complex exudative effusions (parapneumonic, hemothorax, malignant) often demonstrate septations with echogenic strands becoming thicker over time, eventually, thick enough to give a honeycomb-like appearance (Fig. 7.17) [31].

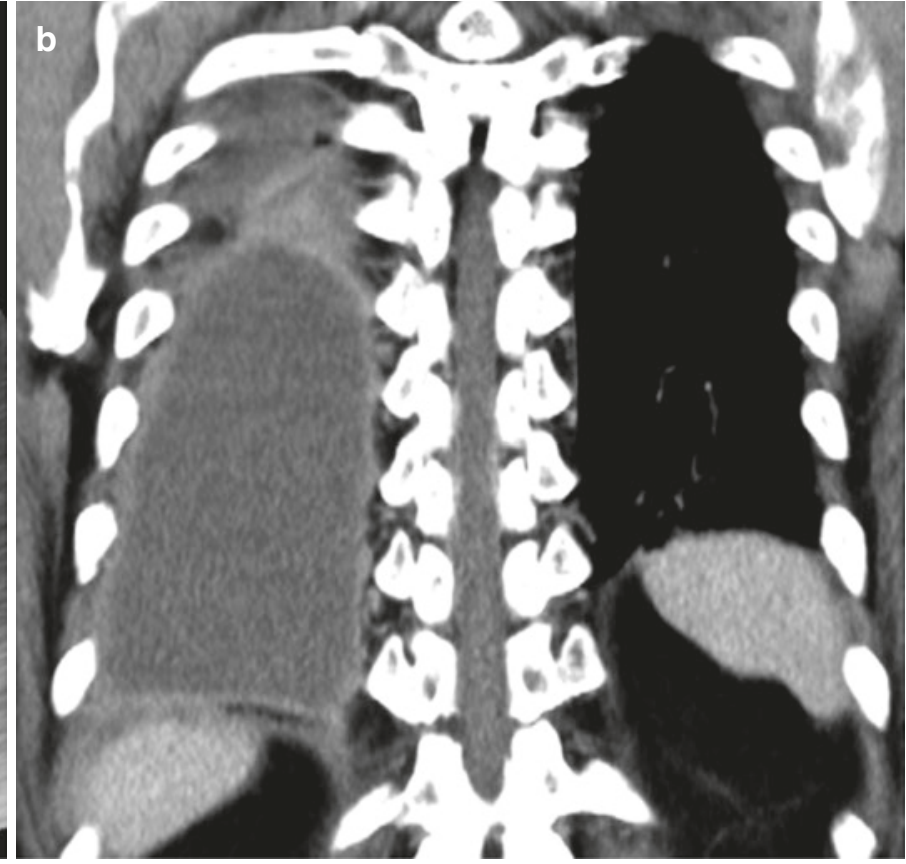

image shows diffuse thickening and enhancement of the parietal pleura suggestive of empyema

\subsection{Tubes and Catheters}

Tubes, lines, and catheters are always present in ICU radiographs. One major use of the radiographs in ICU is to check their position and to evaluate any complications related to their insertion (Table 7.7). 
Table 7.7 Guidelines of lines/tubes in ICU chest radiographs

\begin{tabular}{|c|c|c|c|c|}
\hline Lines/Tubes & Course & Tip & Complications during placement & $\begin{array}{l}\text { Complications } \\
\text { during daily use }\end{array}$ \\
\hline $\begin{array}{l}\text { Nasogastric } \\
\text { tube }\end{array}$ & $\begin{array}{l}\text { Midline course along the } \\
\text { mediastinum, past the carina, } \\
\text { past the diaphragm }\end{array}$ & $\begin{array}{l}10 \mathrm{~cm} \text { past the gastroesophageal } \\
\text { junction }\end{array}$ & $\begin{array}{l}\text { Coiled in mouth } \\
\text { Too distally past the stomach } \\
\text { Pleural cavity } \\
\text { Enteric perforation }\end{array}$ & $\begin{array}{l}\text { Aspiration } \\
\text { Tube migration } \\
\text { Tube breakage }\end{array}$ \\
\hline $\begin{array}{l}\text { Endotracheal } \\
\text { tube }\end{array}$ & Within tracheal lucency & $2-6 \mathrm{~cm}$ proximal to the carina & $\begin{array}{l}\text { Bronchus intubation } \\
\text { Esophageal intubation } \\
\text { Tracheal perforation } \\
\text { Esophageal perforation }\end{array}$ & $\begin{array}{l}\text { Barotrauma } \\
\text { Stenosis }\end{array}$ \\
\hline $\begin{array}{l}\text { Central } \\
\text { catheter }\end{array}$ & $\begin{array}{l}\text { Via (R) internal jugular, into } \\
\text { SVC-catheter should be } \\
\text { vertically orientated } \\
\text { Via }(\mathrm{R}) /(\mathrm{L}) \text { subclavian vein, } \\
\text { into SVC-catheter should } \\
\text { pass below level of the } \\
\text { clavicle, then curves } \\
\text { downward }\end{array}$ & $\begin{array}{l}\text { Lower SVC above cavoatrial } \\
\text { junction }\end{array}$ & $\begin{array}{l}\text { Incorrect intravascular } \\
\text { placement } \\
\text { Into the right atrium/ventricle } \\
\text { Azygos vein } \\
\text { Incorrect extravascular } \\
\text { placement } \\
\text { Pleura } \\
\text { Mediastinum } \\
\text { Pericardium }\end{array}$ & $\begin{array}{l}\text { Catheter } \\
\text { migration }\end{array}$ \\
\hline $\begin{array}{l}\text { Dialysis } \\
\text { catheter }\end{array}$ & Same as central catheters & $\begin{array}{l}\text { Cavoatrial junction } \\
\text { In (R) atrium }\end{array}$ & Same as above & Same as above \\
\hline $\begin{array}{l}\text { Chest tubes } \\
\text { Pleural drains }\end{array}$ & $\begin{array}{l}\text { Anterosuperiorly for } \\
\text { pneumothorax } \\
\text { Posteroinferiorly for pleural } \\
\text { effusion/hemothorax }\end{array}$ & Variable & $\begin{array}{l}\text { Malposition } \\
\text { Lung parenchyma } \\
\text { Interlobar fissure } \\
\text { Subcutaneous tissue } \\
\text { Mediastinum } \\
\text { Pericardium/myocardium } \\
\text { Diaphragm }\end{array}$ & $\begin{array}{l}\text { Re-expansion } \\
\text { pulmonary } \\
\text { edema }\end{array}$ \\
\hline $\begin{array}{l}\text { Swan-Ganz } \\
\text { catheter }\end{array}$ & $\begin{array}{l}\text { From venous system into the } \\
\text { (R) atrium, (R) ventricle, into } \\
\text { pulmonary artery }\end{array}$ & $\begin{array}{l}\text { (When not in use) the tip should be } \\
\text { no more distal than the proximal } \\
\text { interlobar pulmonary artery, ideally } \\
\text { in main pulmonary artery-within } \\
\text { mediastinal shadow. } \\
\text { Must not be }>1 \mathrm{~cm} \text { lateral to } \\
\text { mediastinal margin }\end{array}$ & $\begin{array}{l}\text { Malposition } \\
\text { IVC } \\
\text { Intracardiac }\end{array}$ & $\begin{array}{l}\text { Intracardiac } \\
\text { knotting } \\
\text { Pulmonary } \\
\text { artery rupture } \\
\text { Pulmonary } \\
\text { infarct } \\
\text { Cardiac rupture }\end{array}$ \\
\hline $\begin{array}{l}\text { Intra-aortic } \\
\text { balloon pump }\end{array}$ & $\begin{array}{l}\text { Passes retrograde from the } \\
\text { femoral artery into the } \\
\text { proximal descending thoracic } \\
\text { aorta }\end{array}$ & $\begin{array}{l}\text { Radiopaque marker at tip should } \\
\text { align with the thoracic aorta and lie } \\
\text { just below the aortic arch }\end{array}$ & $\begin{array}{l}\text { Arterial dissection } \\
\text { Malposition }\end{array}$ & $\begin{array}{l}\text { Balloon } \\
\text { migration }\end{array}$ \\
\hline $\begin{array}{l}\text { Pacing leads/ } \\
\text { wires }\end{array}$ & \begin{tabular}{|l} 
Atrial pacing \\
Ventricular pacing
\end{tabular} & $\begin{array}{l}\text { Atrial appendage } \\
\text { Apex }\end{array}$ & $\begin{array}{l}\text { Puncture of the pleura } \\
\text { Puncture of the mediastinum } \\
\text { Puncture of the myocardium }\end{array}$ & $\begin{array}{l}\text { Lead fracture } \\
\text { Lead migration/ } \\
\text { displacement }\end{array}$ \\
\hline
\end{tabular}

\subsubsection{Endotracheal and Tracheostomy Tubes}

Endotracheal tubes (ETT) are used for short-term respiratory support with mechanical ventilation. The tip of endotracheal tube should be located about $5 \mathrm{~cm}$ above the carina when the patient's head is in a neutral position [32]. The neck flexion moves the tube inferiorly by up to $2 \mathrm{~cm}$, and the neck extension moves it superiorly by the same $2 \mathrm{~cm}$, hence the saying "the hose goes with the nose" [5]. Intubation of the main bronchi (most frequently right sided) may result in subsegmental atelectasis (Fig. 7.18), segmental collapse, or complete collapse of the contralateral lung and puts the ipsilateral lung at risk of pneumothorax from overventilation. The too high a position of ETT can lead to inadvertent extubation or damage to the larynx. Overinflation of the endotracheal balloon cuff beyond the normal tracheal diameter chronically can lead to tracheal stenosis or may rarely result in acute rupture [33]. The tracheal rupture however mostly occurs in the peri-intubation period, through the membranous trachea within $7 \mathrm{~cm}$ of the carina [34]. Difficult intubation can occasionally result in hypopharyngeal injury (Fig. 7.19).

Tracheostomy tubes are placed when long-term intubation is necessary. The tracheostomy tube tip should be approximately at mid-T3 level. The tracheostomy tube maintains its position during neck movements. Pneumomediastinum can occur following an uncomplicated tracheostomy tube insertion.

\subsubsection{Enteric Tubes}

Nasogastric tubes are the most commonly used for feeding, medication administration, and suctioning of gastric contents. 

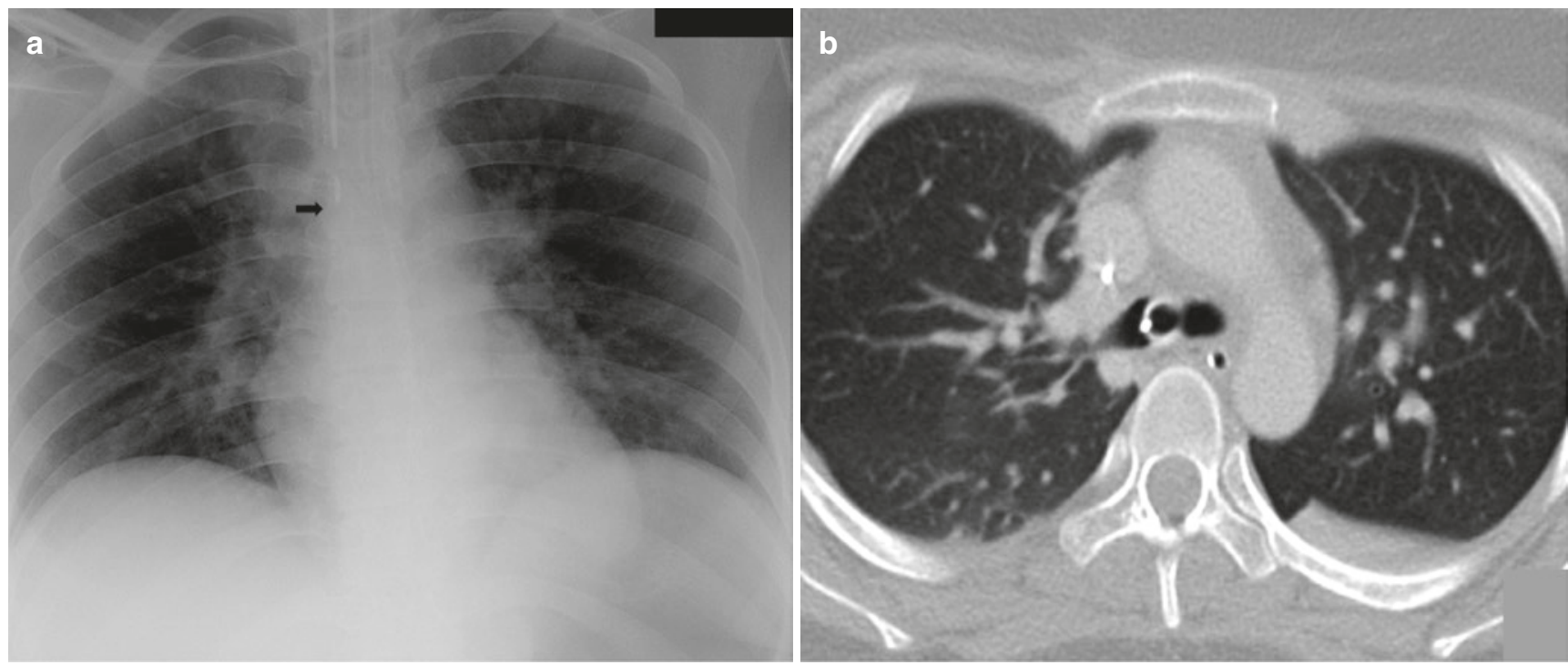

Fig. 7.18 Endotracheal tube malposition. (a) AP chest radiograph shows the tip of the endotracheal tube at the carina. (b) Axial CT image demonstrates the end of the endotracheal tube to be projected in the right main bronchus
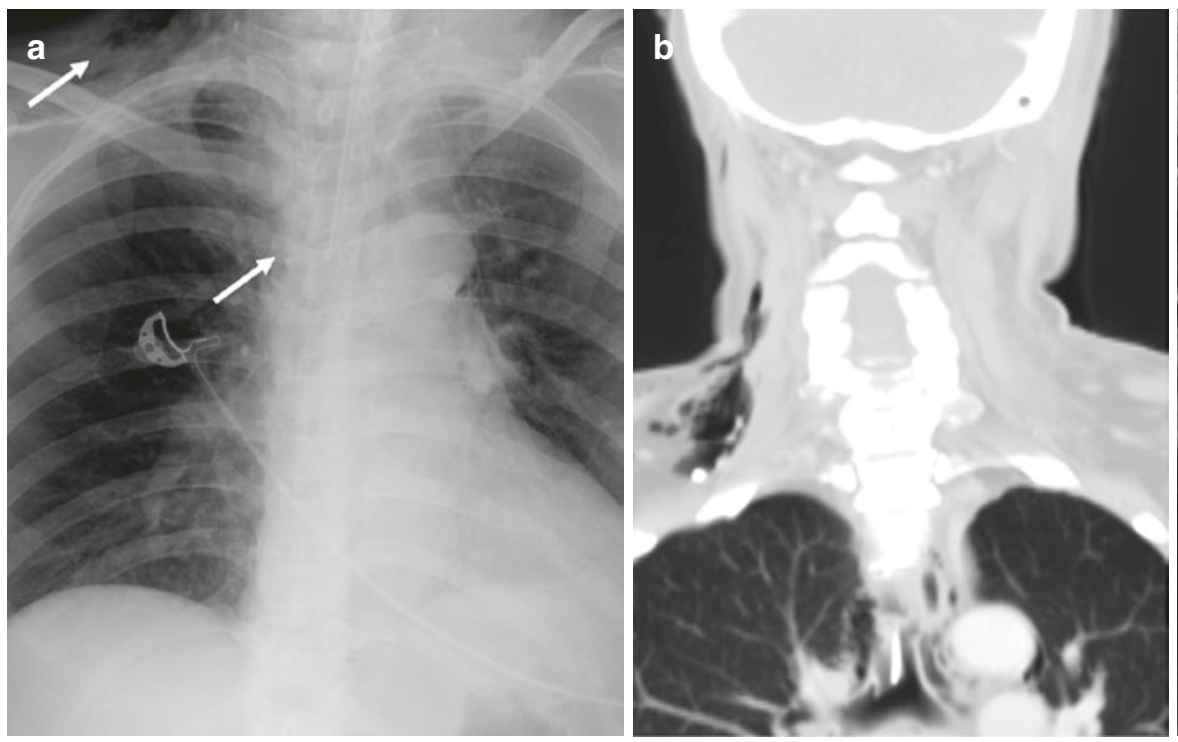

Fig. 7.19 Traumatic intubation. (a) AP chest radiograph demonstrates superior mediastinal and neck base linear and curvilinear lucencies. (b) Coronal CT image confirms pneumomediastinum and neck emphy- sema. (c) Water-soluble contrast study shows a defect in the posterior wall of the hypopharynx

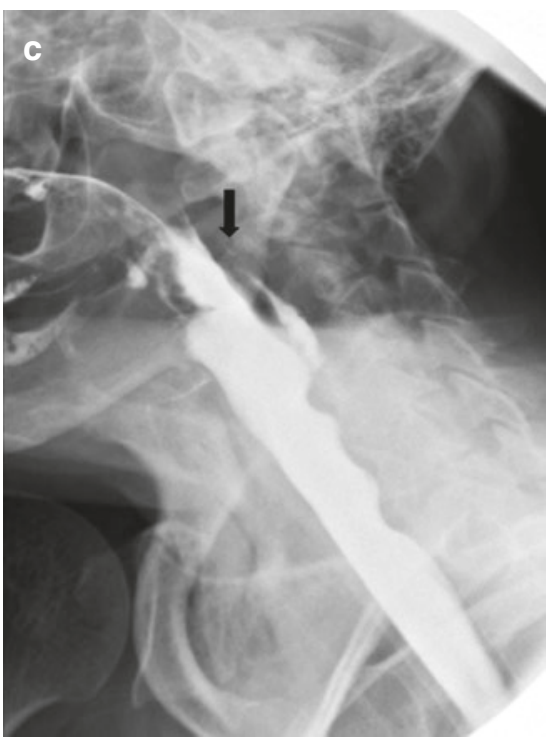

The tip of a feeding tube should be ideally in the antrum of the stomach or distal to it (post-pyloric) to reduce the risk of aspiration. The proximal side hole of a nasogastric tube should extend beyond the gastroesophageal junction [35]. The bedside chest radiograph is the most important investigation to detect tube malposition. The enteric tubes can coil within the pharynx or esophagus, resulting in high risk of aspiration, or very rarely esophageal perforations. The nasogastric tubes occasionally may terminate in the large airways
(Fig. 7.20) where ectopic feeding can result in direct bronchopulmonary injury, pneumonia, pneumothorax, pulmonary laceration, and pulmonary contusion [5].

The gastric feeding tubes are easier to insert than small bowel feeding tubes, allowing early initiation of enteral feeds, and are almost always placed at the time of ICU admission. Small bowel feeding tubes (nasojejunal or percutaneous jejunostomy) are reserved for patients who have high gastric residual volumes despite the use of prokinetics [36]. 

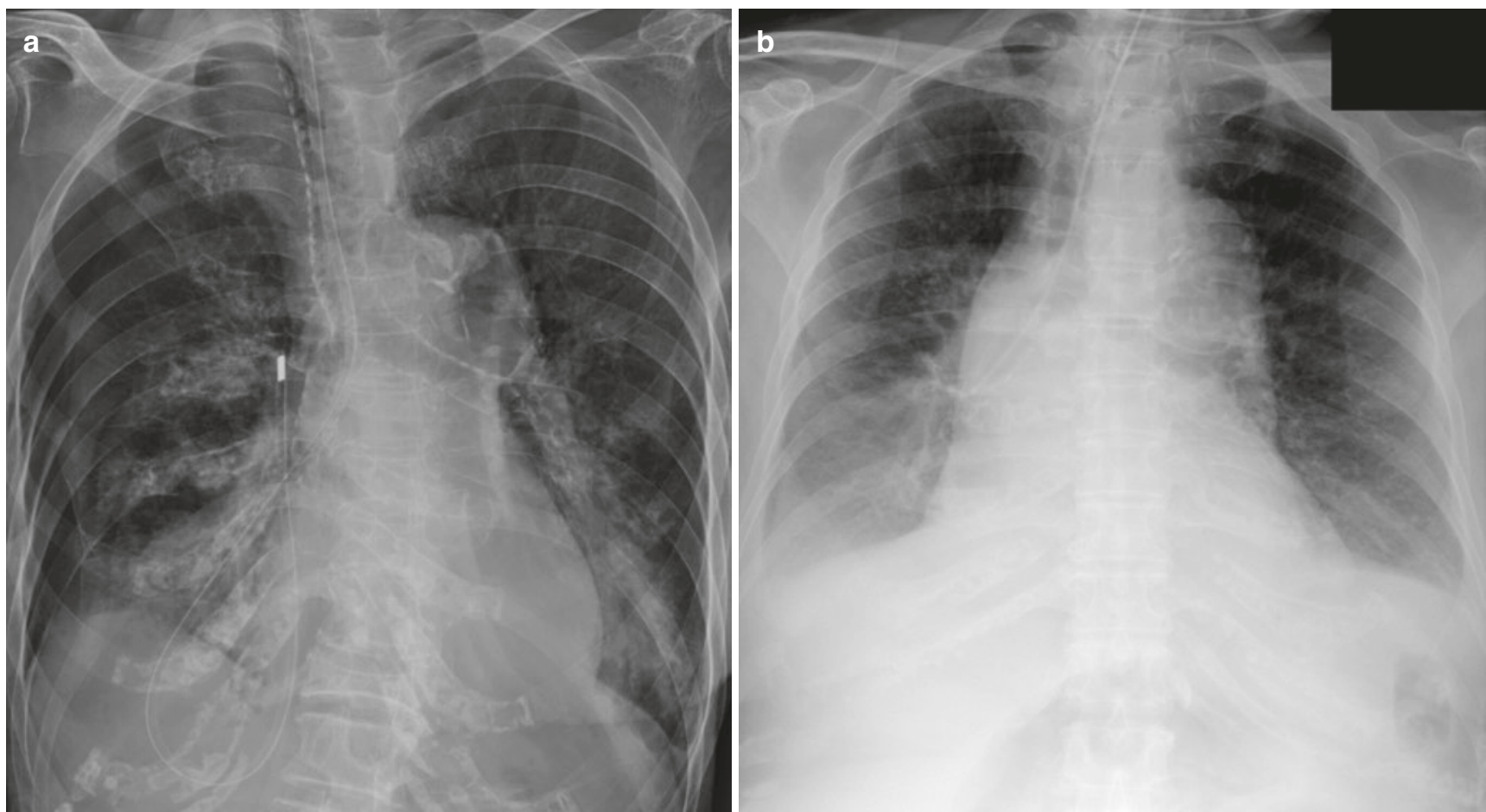

Fig. 7.20 Malpositioned nasogastric tube. (a) AP radiograph shows a nasogastric tube traversing the right main bronchus and coiling in the pleural space with a moderate pneumothorax. (b) AP radiograph in another patient shows feeding tube terminating in the bronchus intermedius
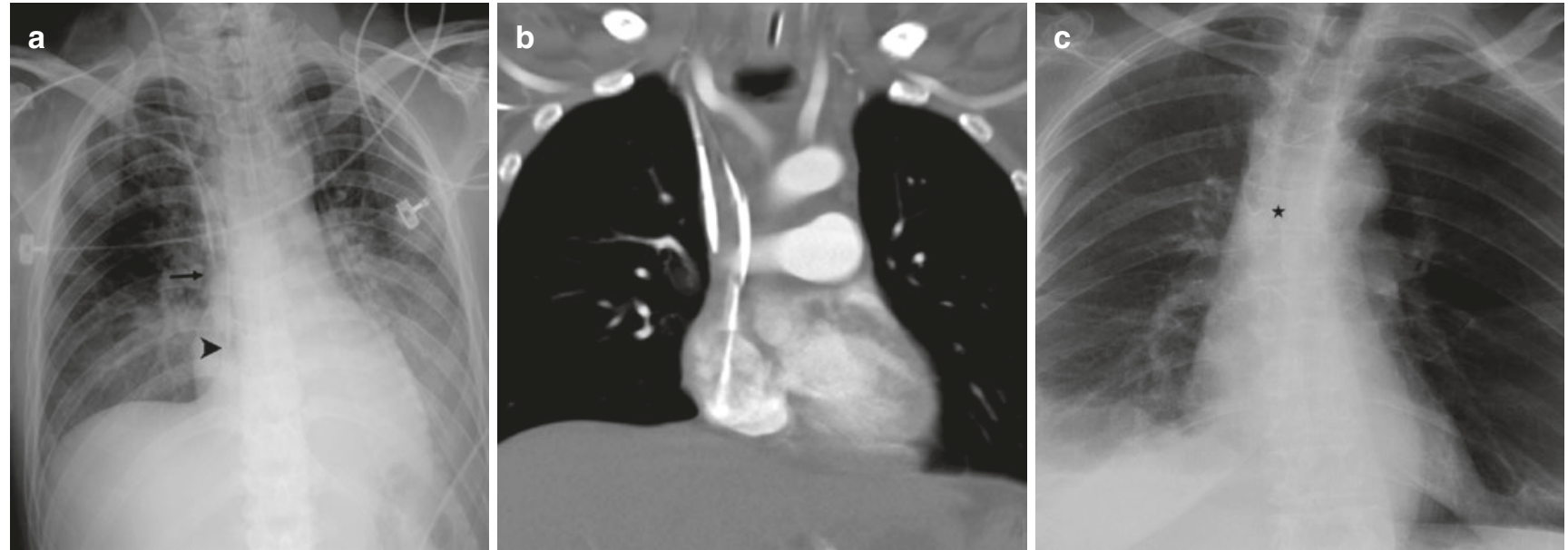

Fig. 7.21 Normal tip position of central venous catheters. (a) AP radiograph shows the tip of the right internal jugular central venous catheter at the level of the bronchus intermedius (arrow) and a right peripherally inserted central catheter (PICC) with its tip $2 \mathrm{~cm}$ caudal to the lower margin of the bronchus intermedius (arrowhead). (b) Coronal CT image confirms the tip of the internal jugular catheter to be in mid/

\subsubsection{Vascular Catheters}

The tip of the central venous catheter should be distal to the last venous valve, which is located at the junction of the internal jugular and the subclavian veins. On the CXR, the position of the valve corresponds to the inner aspect of the anterior first rib [35]. A catheter is more likely to get blocked distal superior vena cava and tip of PICC in the superior cavoatrial junction. Bronchus intermedius on AP chest radiographs serves as a good guide to distal SVC where the tip of central venous catheters should be positioned. (c) Malpositioned PICC in another patient with its tip in azygos vein, characteristically arching in right tracheobronchial angle (asterisk), the expected location of the azygos vein

from thrombosis around it when its position is in proximal SVC or at the thoracic inlet than in the distal SVC or at the cavoatrial junction [37]. The inferior border of bronchus intermedius serves as a good guide to the distal SVC (Fig. 7.21). On the CXR, the cavoatrial junction corresponds to the lower border of the bronchus intermedius, while the arch of azygos is located at the right tracheobronchial angle 

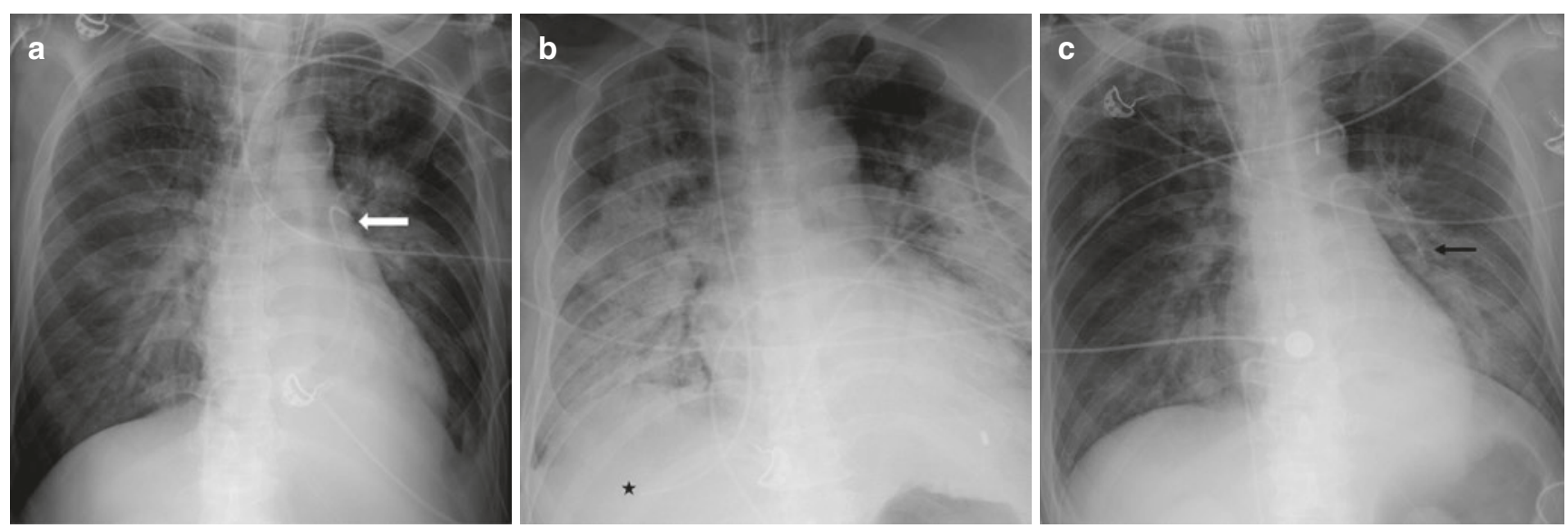

Fig. 7.22 Swan-Ganz catheter. (a) AP chest radiograph demonstrates a Swan-Ganz catheter inserted via the left subclavian vein with its tip at expected location in the left main pulmonary artery and the tip not extending beyond the pulmonary hilum. (b) Chest radiograph in another patient demonstrating an abnormal course of right internal jugular en route Swan-Ganz catheter terminating in the right hepatic vein (asterisk). (c) Distal catheter tip position in the left lower lobe pulmonary artery on a chest radiograph of another ICU patient. This position increases the risk of arterial injury or pulmonary infarct

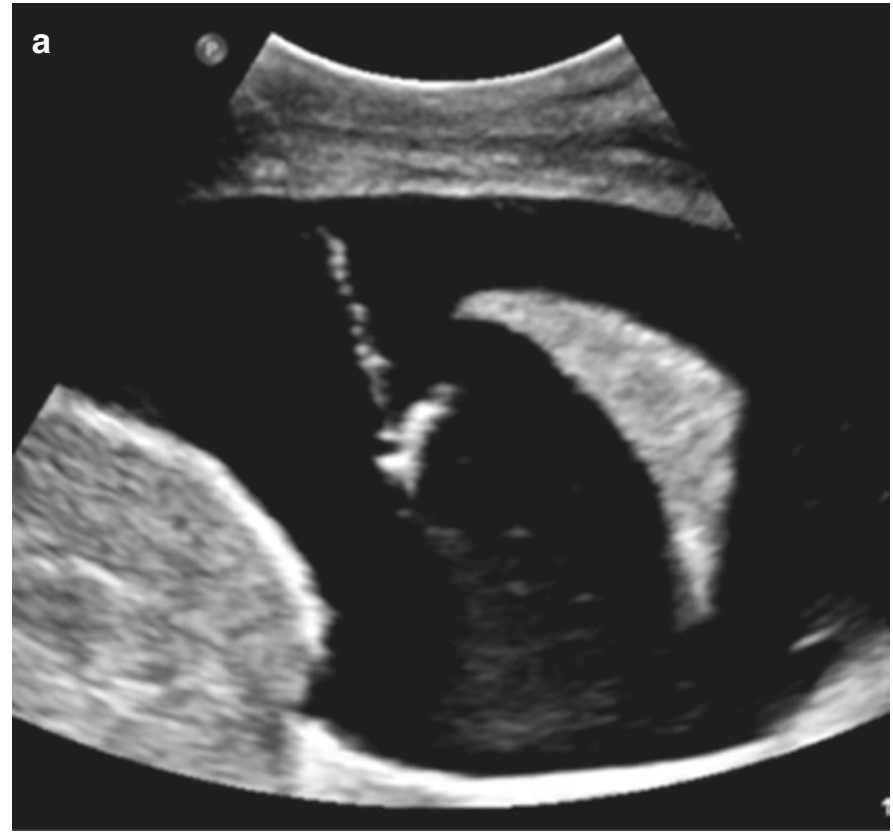

Fig. 7.23 Pleural drain for pleural effusion. (a) Ultrasound image after image-guided insertion of the pleural drainage catheter. A large anechoic pleural effusion is seen with collapsed lower lobe and an

(superior aspect of the origin of the right bronchus from the carina). Tip of any catheter near the right tracheobronchial angle can slip into azygos vein and result in complications. Azygos location of a catheter tip can be identified by its characteristic orientation and position (Fig. 7.21c). Too caudal a position in right atrium increases the risk of dysrhythmia for small caliber peripherally inserted central lines (PICC) and central venous catheters. The right atrial positioning, however, is desirable for large-caliber dialysis catheters. PICC

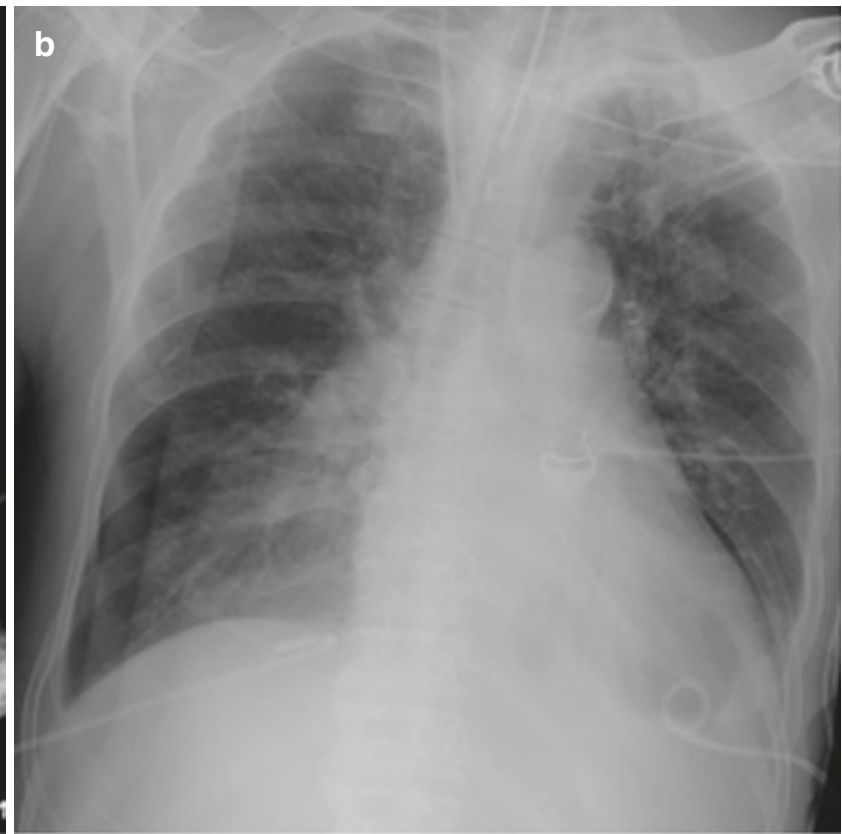

indwelling pigtail drainage catheter whose distal loop is directed toward the posteromedial pleural space, the most dependent portion of the thorax in the supine position. (b) AP chest radiograph shows bilateral pleural drainage catheters directed medially at the lung bases

lines may coil in the veins of the upper extremity, turn cranially into the internal jugular vein, cross to the contralateral brachiocephalic vein, or enter the azygos vein.

Pulmonary artery catheters or Swan-Ganz catheters are placed primarily to measure pulmonary capillary wedge pressure, which helps to differentiate cardiogenic pulmonary edema from non-cardiogenic pulmonary edema. The catheter tip should lie in the main pulmonary arteries or the proximal lobar pulmonary artery (Fig. 7.22). The catheter tip 
should not extend beyond the pulmonary hilum on the chest radiograph [38]. A further distal catheter tip increases the risk of arterial injury and pulmonary infarction. Pulmonary infarcts may also occur secondary to persistent balloon occlusion or pericatheter thrombus.

\subsubsection{Chest Tubes and Pleural Drains}

The proper position of the chest tube depends on the contents to be removed from the pleural cavity. The tip of the tube is directed toward the apex for pneumothorax and toward the lung base for fluid drainage (Fig. 7.23). The side holes of the chest tube, identified on radiographs as interruptions of the tube's radiopaque line, should lie within the pleural space. An improper location of chest tube results in poor drainage and accumulation of air or fluid in the chest wall. The ineffective drainage may also result from tube kinking; blockage resulting from blood clots, pus, or debris in the tube; and apposition of the tip against the mediastinum [33].

An intrafissural location of the tube may or may not affect its function; however, rarely it may result in herniation of lung parenchyma into the holes of chest tube leading to infarction [39]. Inadvertent parenchymal insertion of a chest tube (Fig. 7.24) can lead to pulmonary laceration, hematoma, infarction, and bronchopleural fistula. Besides the lung parenchyma, an inappropriately positioned chest tube can injure the heart, great vessels, diaphragm, liver, and spleen [33].
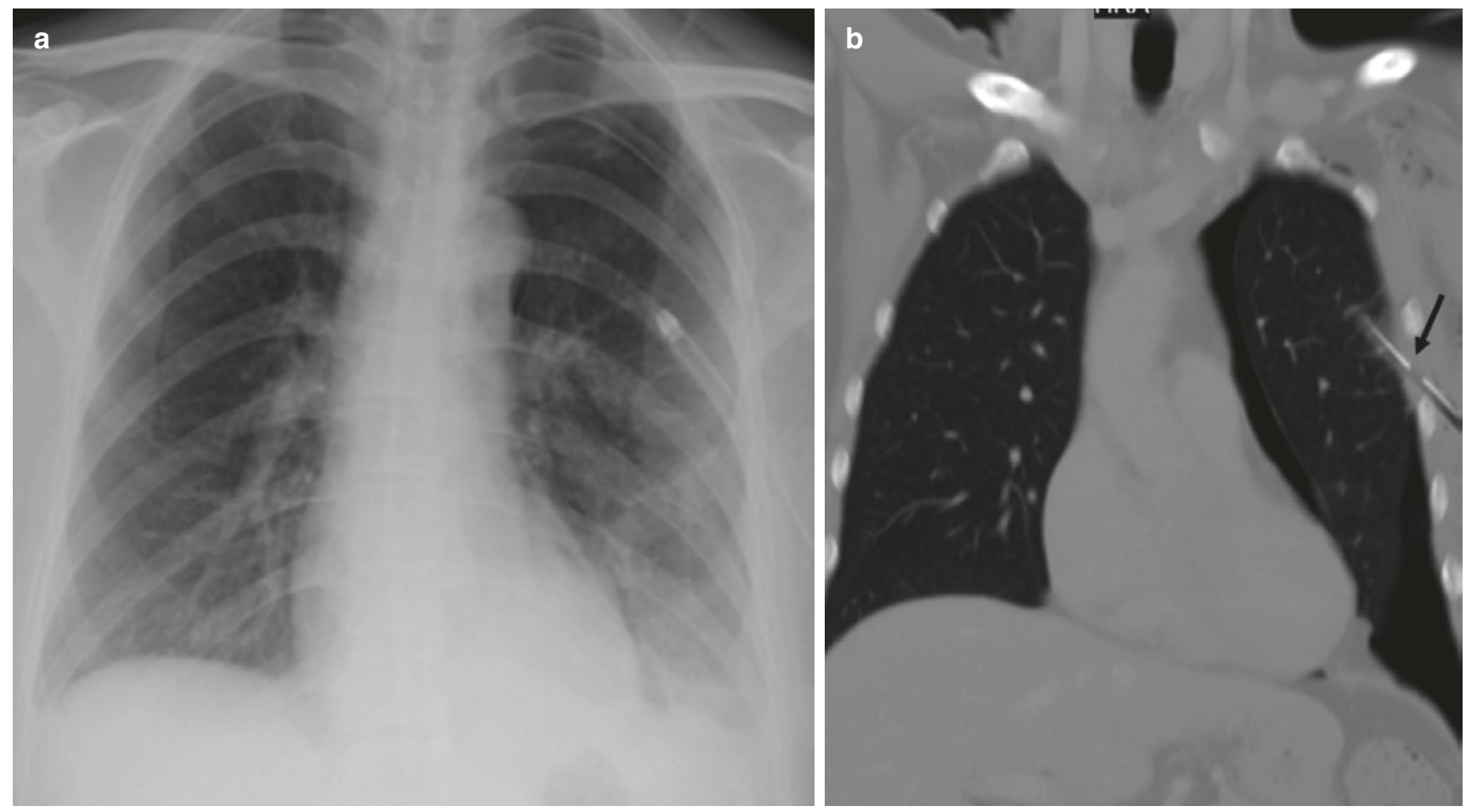

Fig. 7.24 Chest tube for pneumothorax. (a) AP chest radiograph shows a large-bore chest tube directed toward the lung apex for drainage of left pneumothorax. The marking for the side hole is not well seen. (b) Coronal CT image demonstrates the side hole to be outside the pleural cavity responsible for inadequate drainage. (c) AP chest radiograph in another patient after the insertion of chest tube for pneumothorax demonstrates a non-resolving right pneumothorax. (d) Axial CT images show the intraparenchymal course of chest tube 

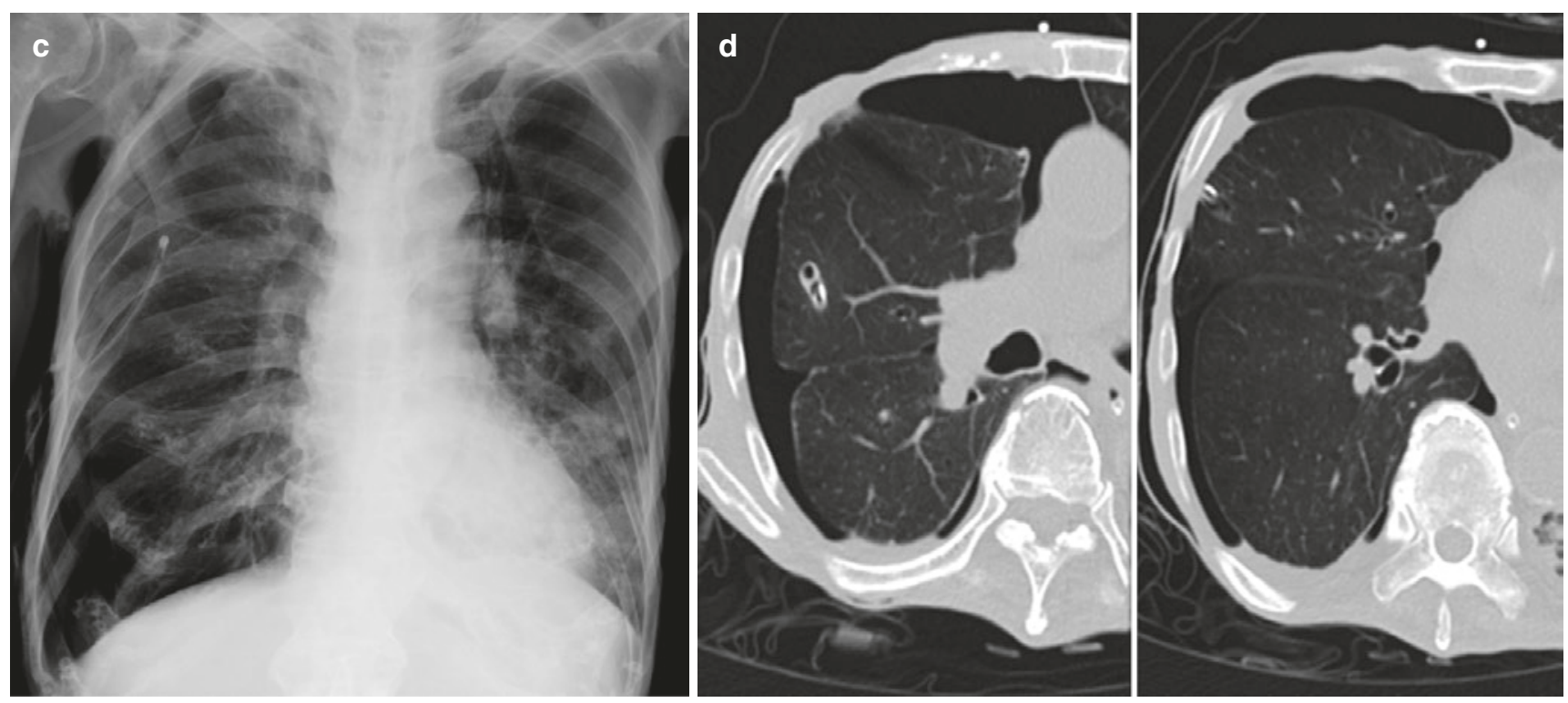

Fig. 7.24 (continued)

Table 7.8 Approach to reporting ICU radiographs

- Compare with as many previous radiographs as possible

- Note the differences in technique, patient position, rotation, and penetration

- Document every new opacity and lucency

- Register the migration of opacities, if any

- Monitor change in mediastinal contour that cannot be explained by the difference in technique and/or rotation

- Mention the site of insertion, course, and tip of all catheters, tubes, and lines

- Check for any prior CT thorax available for any preexisting COPD or fibrotic lung disease

- Wherever possible get the clinical information and answer the question asked in the request form

\subsection{Conclusion}

Interpretation of ICU radiographs is a challenging task. Important pearls for reporting ICU chest radiographs are summarized in Table 7.8.

\section{References}

1. Starling EH. On the absorption of fluids from the connective tissue spaces. J Physiol. 1896;19(4):312-26.

2. Ingram RH Jr, Braunwald E. Dyspnea and pulmonary edema. In: Fauci AS, Braunwald E, Isselbacher KJ, et al., editors. Harrison's principles of internal medicine. 14th ed. New York, NY: McGrawHill; 1998. p. 190-4.

3. Gluecker T, Capasso P, Schnyder P, Gudinchet F, Schaller MD, et al. Clinical and radiologic features of pulmonary edema. Radiographics. 1999;19(6):1507-31.

4. Cardinale L, Volpicelli G, Lamorte A, Martino J, Veltri A. Revisiting signs, strengths and weaknesses of standard chest radiography in patients of acute dyspnea in the emergency department. J Thorac Dis. 2012;4(4):398-407.

5. Bentz MR, Primack SL. Intensive care unit imaging. Clin Chest Med. 2015;36(2):219-34.

6. Definition Task Force ARDS. Acute respiratory distress syndrome: the Berlin definition. JAMA. 2012;307(23):2526-33.

7. Desai SR, Wells AU, Suntharalingam G, Rubens MB, Evans TW, Hansell DM. Acute respiratory distress syndrome caused by pulmonary and extrapulmonary injury: a comparative CT study. Radiology. 2001;218(3):689-93.

8. Rossi SE, Erasmus JJ, Volpacchio M. "Crazy-paving" pattern at thin-section CT of the lungs: radiologic-pathologic overview. Radiographics. 2003;23:1508-19.

9. Ichikado K, Suga M, Muranaka H, Gushima Y, Miyakawa H, Tsubamoto M, et al. Prediction of prognosis for acute respiratory distress syndrome with thin-section CT: validation in 44 cases. Radiology. 2006;238(1):321-9.

10. Shevland JE, Hirleman MT, Hoang KA, Kealey GP. Lobar collapse in the surgical intensive care unit. Br J Radiol. 1983; 56(668):531-4.

11. Morehead RS, Pinto SJ. Ventilator-associated pneumonia. Arch Intern Med. 2000;160:1926-36. 
12. Rubinowitz AN, Siegel MD, Tocino I. Thoracic imaging in ICU. Crit Care Clin. 2007;23(3):539-73.

13. Diederich S. Chest CT for suspected pulmonary complications of oncologic therapies: how I review and report. Cancer Imaging. 2016;16:7.

14. Marom EM, McAdams HP, Erasmus JJ, Goodman PC. The many faces of pulmonary aspiration. AJR Am J Roentgenol. 1999;172(1):121-8.

15. Lichtenberger JP, Digumarthy SR, Abbott GF, Shepard JA, Sharma A. Diffuse pulmonary hemorrhage: clues to the diagnosis. Curr Probl Diagn Radiol. 2014;43(3):128-39.

16. Kang J, Litmanovich D, Bankier AA, Boiselle PM, Eisenberg RL. Manifestations of systemic diseases on thoracic imaging. Curr Probl Diagn Radiol. 2010;39(6):247-61.

17. McLeod AG, Geerts W. Venous thromboembolism prophylaxis in critically ill patients. Crit Care Clin. 2011;27:765-80.

18. Cook D, Attia J, Weaver B, McDonald E, Meade M, Crowther $\mathrm{M}$. Venous thromboembolic disease: an observational study in medical-surgical intensive care unit patients. J Crit Care. 2000;15:127-32.

19. Westermark N. On the roentgen diagnosis of lung embolism. Acta Radiol. 1938;19:357-72.

20. Fleischner FG. Roentgen diagnosis of pulmonary embolism. Heart Bull. 1961;10:104-7.

21. Williams JR, Wilcox WC. Pulmonary embolism: roentgenographic and angiographic considerations. AJR Am J Roentgenol. 1963;89:333.

22. Hampton AO, Castleman B. Correlation of postmortem chest teleroentgenograms with autopsy findings with special reference to pulmonary embolism and infarction. AJR Am J Roentgenol. 1940;43:305-26.

23. Gibson N, Sohne M, Buller H. Prognostic value of echocardiography and spiral computed tomography in patients with pulmonary embolism. Curr Opin Pulm Med. 2005;11(5):380-4.

24. Nikolaou K, Thieme S, Sommer W, Johnson T, Reiser MF. Diagnosing pulmonary embolism: new computed tomography applications. J Thorac Imaging. 2010;25(2):151-60.

25. Yuan R, Shuman WP, Earls JP, Hague CJ, Mumtaz HA, et al. Reduced iodine load at CT pulmonary angiography with dual- energy monochromatic imaging: comparison with standard CT pulmonary angiography - a prospective randomized trial. Radiology. 2012;262(1):290-7.

26. Tocino I, Westcott JL. Barotrauma. Radiol Clin N Am. 1996;34:59-81.

27. Tocino IM, Miller MH, Fairfax WR. Distribution of pneumothorax in the supine and semirecumbent critically ill adult. AJR Am J Roentgenol. 1985;144(5):901-5.

28. Zylak CM, Standen JR, Barnes GR, Zylak CJ. Pneumomediastinum revisited. Radiographics. 2000;20:1043-57.

29. Muller N. Imaging of the pleura. Radiology. 1993;186:297-309.

30. Kuhlman JE, Sinha NK. Complex disease of the pleural space: radiographic and CT evaluation. Radiographics. 1997;17(1):63-79.

31. Hallifax RJ, Talwar A, Wrightson JM, Edey A, Gleeson FV. Stateof-the-art: radiological investigation of pleural disease. Respir Med. 2017;124:88-99.

32. Goodman LR, Conrardy PA, Laing F, Singer MM. Radiographic evaluation of endotracheal tube position. AJR Am J Roentgenol. 1976;127(3):433-4.

33. Godoy MC, Leitman BS, de Groot PM, Vlahos I, Naidich DP. Chest radiography in the ICU: part 1, evaluation of airway, enteric, and pleural tubes. AJR Am J Roentgenol. 2012;198(3):563-71.

34. Rollins RJ, Tocino I. Early radiographic signs of tracheal rupture. AJR Am J Roentgenol. 1987;148:695-8.

35. Godoy MC, Leitman BS, de Groot PM, Vlahos I, Naidich DP. Chest radiography in the ICU: part 2, evaluation of cardiovascular lines and other devices. AJR Am J Roentgenol. 2012;198(3):572-81.

36. Marik PE, Zaloga GP. Gastric versus post-pyloric feeding: a systematic review. Crit Care. 2003;7(3):R46-51.

37. Cadman A, Lawrance JA, Fitzsimmons L, Spencer-Shaw A, Swindell R. To clot or not to clot? That is the question in central venous catheters. Clin Radiol. 2004;59:349-55.

38. Kazerooni EA, Gross BH. Lines, tubes, and devices. In: Kazerooni EA, Gross BH, editors. Cardiopulmonary imaging. Philadelphia: Lippincott Williams \& Wilkins; 2004. p. 255-93.

39. Stahly TL, Tench WD. Lung entrapment and infarction by chest tube suction. Radiology. 1977;122:307-9. 